\title{
Impact of minor structural modifications on properties of a series of mTOR inhibitors
}

Gilles Ouvry, ${ }^{*}$ Laurence Clary, Loïc Tomas, Michèle Aurelly, Laetitia Bonnary, Emilie Borde, Claire Bouix-Peter, Laurent Chantalat, Claire Defoin-Platel, Sophie Deret, Mathieu Forissier, Craig S. Harris, Tatiana Isabet, Laurent Lamy, Anne-Pascale Luzy, Jonathan Pascau, Catherine Soulet, Alessandro Taddei, Nathalie Taquet, Etienne Thoreau, Emeric Varvier, Emmanuel Vial and Laurent F. Hennequin

\section{Contents of SI}

Solubility in $\mathrm{H} 2 \mathrm{O}$

\section{ChromLogD}

Reference and test compounds are solubilized in methanol at $0.5 \mathrm{mM}$. An aliquot was injected onto the UPLC/UV system and the retention times (RT) were measured with different mobile phases at $\mathrm{pH}$ 6.5. A calibration curve was performed with reference compounds by plotting the highest RT of each compound. The RT measured for each test compound was converted to Chromatographic Hydrophobicity Index $(\mathrm{CHI})$ value by using the calibration curve established with reference compounds. ${ }^{1}$ The $\mathrm{CHI}$ was then converted to ChromLogD using the equation established by Young: $\mathrm{CHI} 0.0857-2 .^{2}$

\section{Solubility in $\mathrm{H}_{2} \mathrm{O}$}

Compounds from a stock solution in DMSO $(10 \mathrm{mM})$ were dissolved at $100 \mu \mathrm{M}$ into a phosphate buffer solution pH7.4 and were shaken during $24 \mathrm{H}$ at $20^{\circ} \mathrm{C}$.

After filtration and dilution, the samples were quantified using a High performance liquid chromatography method by comparison from standards. 


\section{Human microsome metabolic stability}

Human liver microsomes are used (pooled from a 35 individuals for human). Incubations are performed at a test compound concentration of $1 \mu \mathrm{M}$ at $37^{\circ} \mathrm{C}$ with $0.5 \mathrm{mg}$ protein $/ \mathrm{mL}$ in presence of phase I metabolism cofactors. The final DMSO concentration in the incubation is $0.1 \%$. Control incubations are also performed in lysed microsomes to reveal any non-enzymatic degradation. Control compound (phase 1 metabolism) is included. Samples $(65 \mu \mathrm{L})$ are removed from the incubation mixture at 0 and $15 \mathrm{~min}$ and added to acetonitrile:water (75:25), containing internal standard, $(175 \mu \mathrm{L})$ to stop the reaction. Samples are analyzed by LC-MS/MS. \% Parent Compound at $15 \mathrm{~min}$ is calculated.

\section{Human hepatocytes metabolic stability}

Suspension of cryopreserved human hepatocytes was used (pooled from a 10 individuals). Incubations were performed at a test compound concentration of $1 \mu \mathrm{M}$ at $37^{\circ} \mathrm{C}$ and $5 \% \mathrm{CO} 2$. The cell density was $0.5 \times 106$ viable cells $/ \mathrm{ml}$. The final DMSO concentration in the incubation is $0.1 \%$. Control incubations were also performed in lysed cells to reveal any non-enzymatic degradation. Two control

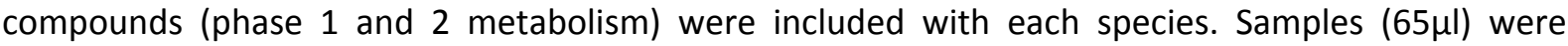
removed from the incubation mixture at $0,5,15,30,60$ and 90 min (control sample at 90min only) and added to acetonitrile:water (75:25), containing internal standard, $(175 \mu l)$ to stop the reaction. Samples were analyzed by LC-MS/MS. Half-life and intrinsic clearance were calculated.

\section{Biochemical assay}

mTOR biochemical LanthaScreen ${ }^{\mathrm{TM}}$ assays were performed in a $10 \mu \mathrm{L}$ volume in low-volume 384-well plates (Corning 4514). According to the manufacturer (Lifetechnologies), the concentration of substrate was $400 \mathrm{nM}$, and the $1 x$ kinase reaction buffer consisted of $50 \mathrm{mM}$ HEPES pH 7.5, $0.01 \%$ Tween 20, $1 \mathrm{mM}$ EGTA, $10 \mathrm{mM} \mathrm{MnCl}_{2}$, and $2 \mathrm{mM}$ DTT. Reactions were allowed to proceed for 1 hour (linear phase) at room temperature in the presence and in the absence of compounds at $1 \%$ DMSO before a $10 \mu \mathrm{L}$ preparation of EDTA $(20 \mathrm{mM})$ and Tb-labeled antibody (4 $\mathrm{nM})$ in TR-FRET dilution buffer were added. The final concentrations of antibody and EDTA in the assay were $2 \mathrm{nM}$ and 10 $\mathrm{mM}$ respectively. Plates were allowed to incubate at room temperature for at least 30 minutes before being red on a plate reader configured for LanthaScreen ${ }^{\text {TM }}$ TR-FRET.

For PI3K $\alpha$, enzymatic reaction was performed in a $10 \mu \mathrm{L}$ volume, using low-volume 384-well plates (Corning 4514). The concentration of substrate (PIP2) was $10 \mu \mathrm{M}$, and the $1 \mathrm{X}$ kinase reaction buffer consisted of proprietary EUROFIN buffer plus $5 \mathrm{mM}$ DTT. Kinase reaction was allowed to proceed for 30 minutes (linear phase) at room temperature before a $10 \mu \mathrm{L}$ preparation of STOP solution (STOP A and $B$ ) and Detection mix (DMC A, B and C) were added. Plate was incubated at room temperature for at least 2 hours before being read on a plate reader configured for TR-FRET. 


\section{Cellular assay}

A431 cells were seeded on poly-L-lysine coated plates at 25000 cells/well in DMEM medium. Before experiments cells were starved and maintained in culture for 24 hours. The day of the experiment cells were treated with increasing compounds concentrations (final DMSO\%=0.1) for 3 hours and level of phosphorylated S6RP (Ser235/236) and AKT (Ser473) were measured by HTRF (CISBIO) kit following protocols of the provider.

\section{DiscoveRx ScanMax Kinome Binding Scan}

Compounds were tested at $10 \mu \mathrm{M}$ concentration against a panel of 442 known protein kinases. Data are presented as percent of control activity remaining. ( $0 \%$ indicates very tight binders, $100 \%$ indicates no binding).

\begin{tabular}{|c|c|c|c|c|c|c|c|c|c|c|}
\hline & & $\begin{array}{l}\text { Percent } \\
\text { Control }\end{array}$ & & & & & & & & \\
\hline DiscoveRx Gene Symbol & Entrez Gene Symbol & $4 a$ & $3 e$ & $3 \mathbf{j}$ & $3 k$ & $6 a$ & 1 & $6 e$ & $3 b$ & $4 b$ \\
\hline AAK1 & AAK1 & 92 & 67 & 81 & 27 & 49 & 77 & 73 & 81 & 49 \\
\hline ABL1(E255K)-phosphorylated & ABL1 & 92 & 29 & 22 & 0.8 & 66 & 2.4 & 74 & 57 & 93 \\
\hline ABL1(F317I)-nonphosphorylated & ABL1 & 95 & 90 & 79 & 79 & 84 & 94 & 100 & 100 & 100 \\
\hline ABL1(F317I)-phosphorylated & ABL1 & 66 & 50 & 54 & 41 & 73 & 21 & 100 & 100 & 100 \\
\hline ABL1(F317L)-nonphosphorylated & ABL1 & 93 & 81 & 33 & 62 & 60 & 35 & 100 & 100 & 100 \\
\hline ABL1(F317L)-phosphorylated & ABL1 & 78 & 31 & 15 & 20 & 46 & 4.6 & 100 & 89 & 99 \\
\hline ABL1(H396P)-nonphosphorylated & ABL1 & 78 & 26 & 13 & 0.25 & 17 & 0.15 & 74 & 65 & 70 \\
\hline ABL1(H396P)-phosphorylated & ABL1 & 82 & 49 & 28 & 0.1 & 49 & 3.4 & 87 & 69 & 100 \\
\hline ABL1(M351T)-phosphorylated & ABL1 & 84 & 56 & 36 & 0.4 & 50 & 5.3 & 100 & 92 & 100 \\
\hline ABL1(Q252H)-nonphosphorylated & ABL1 & 80 & 15 & 11 & 0.65 & 46 & 0.4 & 86 & 46 & 93 \\
\hline ABL1(Q252H)-phosphorylated & ABL1 & 90 & 39 & 22 & 0.3 & 19 & 5 & 100 & 100 & 100 \\
\hline ABL1(T315I)-nonphosphorylated & ABL1 & 98 & 100 & 80 & 2.7 & 81 & 64 & 100 & 100 & 100 \\
\hline ABL1(T315I)-phosphorylated & ABL1 & 90 & 75 & 80 & 0.8 & 78 & 44 & 93 & 96 & 99 \\
\hline ABL1(Y253F)-phosphorylated & ABL1 & 71 & 47 & 22 & 0.15 & 41 & 6 & 100 & 89 & 100 \\
\hline ABL1-nonphosphorylated & ABL1 & 54 & 29 & 16 & 0.25 & 64 & 2.8 & 54 & 44 & 80 \\
\hline ABL1-phosphorylated & ABL1 & 72 & 42 & 24 & 0.2 & 82 & 4.3 & 72 & 71 & 87 \\
\hline$A B L 2$ & $A B L 2$ & 96 & 63 & 74 & 21 & 100 & 36 & 97 & 93 & 100 \\
\hline ACVR1 & ACVR1 & 88 & 96 & 81 & 62 & 100 & 0.55 & 100 & 100 & 91 \\
\hline ACVR1B & ACVR1B & 100 & 96 & 84 & 88 & 87 & 13 & 86 & 90 & 100 \\
\hline ACVR2A & ACVR2A & 85 & 95 & 98 & 100 & 100 & 3.8 & 76 & 97 & 93 \\
\hline ACVR2B & ACVR2B & 88 & 98 & 99 & 98 & 100 & 6.3 & 54 & 80 & 86 \\
\hline ACVRL1 & ACVRL1 & 67 & 73 & 72 & 96 & 100 & 24 & 89 & 100 & 94 \\
\hline ADCK3 & CABC1 & 85 & 60 & 31 & 99 & 95 & 90 & 87 & 86 & 91 \\
\hline ADCK4 & ADCK4 & 99 & 100 & 68 & 68 & 100 & 75 & 84 & 95 & 79 \\
\hline AKT1 & AKT1 & 95 & 100 & 88 & 100 & 100 & 67 & 97 & 98 & 100 \\
\hline AKT2 & AKT2 & 92 & 100 & 75 & 83 & 98 & 80 & 86 & 100 & 100 \\
\hline AKT3 & AKT3 & 100 & 100 & 100 & 100 & 96 & 44 & 100 & 84 & 91 \\
\hline ALK & ALK & 100 & 99 & 86 & 31 & 72 & 78 & 100 & 100 & 100 \\
\hline ALK(C1156Y) & ALK & 100 & 84 & 90 & 26 & 64 & 33 & 97 & 90 & 87 \\
\hline ALK(L1196M) & ALK & 93 & 95 & 99 & 35 & 72 & 92 & 97 & 97 & 92 \\
\hline
\end{tabular}




\begin{tabular}{|c|c|c|c|c|c|c|c|c|c|c|}
\hline AMPK-alpha1 & PRKAA1 & 80 & 83 & 86 & 69 & 100 & 92 & 100 & 100 & 100 \\
\hline AMPK-alpha2 & PRKAA2 & 87 & 98 & 81 & 87 & 100 & 79 & 77 & 100 & 100 \\
\hline ANKK1 & ANKK1 & 76 & 88 & 54 & 9.9 & 64 & 95 & 100 & 100 & 100 \\
\hline ARK5 & NUAK1 & 100 & 92 & 91 & 33 & 66 & 95 & 100 & 89 & 100 \\
\hline ASK1 & MAP3K5 & 95 & 99 & 99 & 23 & 100 & 100 & 100 & 100 & 96 \\
\hline ASK2 & МАР3К6 & 100 & 100 & 91 & 49 & 70 & 99 & 100 & 100 & 98 \\
\hline AURKA & AURKA & 99 & 91 & 90 & 16 & 100 & 63 & 95 & 92 & 100 \\
\hline AURKB & AURKB & 100 & 99 & 63 & 26 & 90 & 72 & 100 & 94 & 98 \\
\hline AURKC & AURKC & 58 & 74 & 79 & 33 & 73 & 69 & 79 & 96 & 89 \\
\hline$A X L$ & AXL & 100 & 90 & 61 & 19 & 91 & 34 & 87 & 86 & 96 \\
\hline BIKE & BMP2K & 15 & 52 & 70 & 16 & 25 & 63 & 59 & 78 & 75 \\
\hline BLK & BLK & 67 & 34 & 18 & 5.8 & 87 & 3.1 & 88 & 97 & 100 \\
\hline BMPR1A & BMPR1A & 87 & 81 & 100 & 94 & 92 & 18 & 83 & 99 & 100 \\
\hline BMPR1B & BMPR1B & 69 & 62 & 41 & 8.1 & 83 & 0.05 & 93 & 86 & 93 \\
\hline BMPR2 & BMPR2 & 99 & 97 & 89 & 19 & 42 & 53 & 98 & 79 & 100 \\
\hline BMX & BMX & 95 & 93 & 95 & 41 & 85 & 76 & 88 & 99 & 100 \\
\hline BRAF & BRAF & 71 & 53 & 43 & 57 & 88 & 36 & 100 & 82 & 63 \\
\hline BRAF(V600E) & BRAF & 72 & 43 & 22 & 55 & 80 & 21 & 96 & 80 & 57 \\
\hline BRK & PTK6 & 83 & 73 & 19 & 75 & 100 & 26 & 68 & 99 & 96 \\
\hline BRSK1 & BRSK1 & 96 & 91 & 85 & 90 & 100 & 99 & 100 & 100 & 96 \\
\hline BRSK2 & BRSK2 & 81 & 89 & 85 & 92 & 94 & 71 & 72 & 85 & 100 \\
\hline BTK & BTK & 98 & 100 & 95 & 6.4 & 93 & 100 & 100 & 100 & 100 \\
\hline BUB1 & BUB1 & 77 & 72 & 77 & 16 & 57 & 86 & 100 & 99 & 100 \\
\hline CAMK1 & CAMK1 & 68 & 73 & 71 & 12 & 98 & 57 & 66 & 88 & 48 \\
\hline CAMK1B & PNCK & 100 & 100 & 100 & 24 & 100 & 66 & 80 & 100 & 79 \\
\hline CAMK1D & CAMK1D & 83 & 78 & 67 & 19 & 94 & 53 & 77 & 85 & 72 \\
\hline CAMK1G & CAMK1G & 95 & 82 & 86 & 54 & 100 & 87 & 100 & 100 & 76 \\
\hline САМК2A & CAMK2A & 98 & 100 & 78 & 85 & 100 & 46 & 90 & 91 & 96 \\
\hline CAMK2B & CAMK2B & 93 & 100 & 84 & 89 & 100 & 60 & 89 & 90 & 88 \\
\hline CAMK2D & CAMK2D & 92 & 86 & 76 & 84 & 97 & 52 & 94 & 94 & 86 \\
\hline CAMK2G & CAMK2G & 96 & 79 & 68 & 80 & 94 & 38 & 67 & 87 & 64 \\
\hline САМК 4 & CAMK4 & 61 & 80 & 82 & 100 & 99 & 68 & 93 & 97 & 100 \\
\hline CAMKK1 & CAMKK1 & 100 & 91 & 100 & 100 & 83 & 73 & 80 & 79 & 75 \\
\hline CAMKK2 & САМКK2 & 86 & 74 & 73 & 67 & 90 & 65 & 77 & 83 & 58 \\
\hline CASK & CASK & 78 & 81 & 45 & 70 & 67 & 31 & 99 & 81 & 94 \\
\hline CDC2L1 & CDK11B & 89 & 96 & 86 & 92 & 100 & 100 & 93 & 99 & 91 \\
\hline $\mathrm{CDC} 2 \mathrm{~L} 2$ & $\mathrm{CDC} 2 \mathrm{~L} 2$ & 100 & 100 & 98 & 94 & 97 & 94 & 98 & 92 & 66 \\
\hline CDC2L5 & CDK13 & 100 & 94 & 91 & 87 & 77 & 100 & 100 & 100 & 100 \\
\hline CDK11 & CDK19 & 85 & 98 & 86 & 85 & 99 & 21 & 100 & 96 & 100 \\
\hline CDK2 & CDK2 & 100 & 100 & 93 & 100 & 98 & 81 & 83 & 90 & 100 \\
\hline CDK3 & CDK3 & 100 & 94 & 100 & 100 & 91 & 85 & 86 & 92 & 93 \\
\hline CDK4 & CDK4 & 100 & 100 & 100 & 100 & 94 & 92 & 100 & 100 & 100 \\
\hline CDK4-cyclinD1 & CDK4 & 99 & 90 & 99 & 89 & 66 & 100 & 100 & 100 & 100 \\
\hline CDK4-cyclinD3 & CDK4 & 93 & 100 & 97 & 95 & 73 & 100 & 100 & 97 & 100 \\
\hline CDK5 & CDK5 & 90 & 92 & 93 & 100 & 92 & 89 & 87 & 85 & 100 \\
\hline CDK7 & CDK7 & 93 & 100 & 79 & 93 & 69 & 64 & 98 & 93 & 100 \\
\hline
\end{tabular}




\begin{tabular}{|c|c|c|c|c|c|c|c|c|c|c|}
\hline CDK8 & CDK8 & 100 & 100 & 95 & 100 & 100 & 42 & 100 & 100 & 100 \\
\hline CDK9 & CDK9 & 87 & 100 & 87 & 93 & 100 & 100 & 98 & 99 & 100 \\
\hline CDKL1 & CDKL1 & 80 & 60 & 70 & 91 & 97 & 66 & 85 & 59 & 88 \\
\hline CDKL2 & CDKL2 & 89 & 89 & 96 & 100 & 94 & 55 & 93 & 93 & 98 \\
\hline CDKL3 & CDKL3 & 79 & 78 & 79 & 97 & 85 & 72 & 81 & 82 & 100 \\
\hline CDKL5 & CDKL5 & 85 & 90 & 94 & 100 & 100 & 100 & 100 & 100 & 100 \\
\hline CHEK1 & CHEK1 & 97 & 96 & 88 & 59 & 100 & 92 & 100 & 93 & 81 \\
\hline CHEK2 & CHEK2 & 91 & 81 & 79 & 37 & 80 & 81 & 88 & 96 & 55 \\
\hline СIT & СІT & 84 & 76 & 81 & 89 & 76 & 76 & 79 & 88 & 86 \\
\hline CLK1 & CLK1 & 89 & 65 & 65 & 24 & 57 & 71 & 92 & 81 & 85 \\
\hline CLK2 & CLK2 & 96 & 95 & 63 & 27 & 40 & 64 & 71 & 79 & 82 \\
\hline CLK3 & CLK3 & 80 & 91 & 84 & 69 & 100 & 68 & 97 & 84 & 100 \\
\hline CLK4 & CLK4 & 72 & 93 & 62 & 46 & 62 & 76 & 84 & 86 & 100 \\
\hline CSF1R & CSF1R & 100 & 42 & 12 & 0.05 & 30 & 0.45 & 100 & 79 & 59 \\
\hline CSF1R-autoinhibited & CSF1R & 100 & 90 & 72 & 0.1 & 37 & 6.2 & 100 & 77 & 97 \\
\hline CSK & CSK & 94 & 99 & 95 & 20 & 100 & 56 & 75 & 86 & 91 \\
\hline CSNK1A1 & CSNK1A1 & 87 & 56 & 22 & 54 & 100 & 5.1 & 58 & 87 & 95 \\
\hline CSNK1A1L & CSNK1A1L & 84 & 69 & 25 & 54 & 100 & 15 & 96 & 79 & 100 \\
\hline CSNK1D & CSNK1D & 71 & 57 & 5.3 & 60 & 100 & 3.4 & 98 & 72 & 77 \\
\hline CSNK1E & CSNK1E & 69 & 43 & 1.2 & 58 & 100 & 0.5 & 100 & 66 & 85 \\
\hline CSNK1G1 & CSNK1G1 & 94 & 98 & 95 & 78 & 99 & 93 & 75 & 86 & 93 \\
\hline CSNK1G2 & CSNK1G2 & 76 & 70 & 60 & 48 & 100 & 65 & 98 & 100 & 100 \\
\hline CSNK1G3 & CSNK1G3 & 78 & 62 & 55 & 67 & 100 & 56 & 100 & 90 & 79 \\
\hline CSNK2A1 & CSNK2A1 & 100 & 100 & 97 & 66 & 70 & 95 & 100 & 96 & 100 \\
\hline CSNK2A2 & CSNK2A2 & 100 & 86 & 98 & 74 & 86 & 92 & 81 & 88 & 73 \\
\hline CTK & MATK & 91 & 98 & 79 & 62 & 72 & 54 & 100 & 73 & 98 \\
\hline DAPK1 & DAPK1 & 99 & 94 & 82 & 61 & 93 & 74 & 75 & 84 & 83 \\
\hline DAPK2 & DAPK2 & 100 & 88 & 72 & 65 & 96 & 63 & 65 & 86 & 92 \\
\hline DAPK3 & DAPK3 & 88 & 90 & 85 & 62 & 100 & 88 & 80 & 85 & 96 \\
\hline DCAMKL1 & DCLK1 & 78 & 92 & 90 & 100 & 81 & 88 & 90 & 77 & 94 \\
\hline DCAMKL2 & DCLK2 & 100 & 100 & 94 & 99 & 89 & 99 & 100 & 98 & 75 \\
\hline DCAMKL3 & DCLK3 & 78 & 36 & 45 & 54 & 100 & 39 & 94 & 90 & 100 \\
\hline DDR1 & DDR1 & 88 & 43 & 24 & 78 & 100 & 3.7 & 100 & 89 & 66 \\
\hline DDR2 & DDR2 & 100 & 76 & 50 & 67 & 94 & 0.85 & 100 & 100 & 89 \\
\hline DLK & МАРЗК12 & 97 & 99 & 100 & 66 & 11 & 71 & 20 & 48 & 71 \\
\hline DMPK & DMPK & 66 & 72 & 100 & 84 & 98 & 100 & 91 & 92 & 89 \\
\hline DMPK2 & CDC42BPG & 93 & 97 & 93 & 92 & 100 & 68 & 100 & 95 & 81 \\
\hline DRAK1 & STK17A & 89 & 92 & 78 & 25 & 100 & 95 & 83 & 100 & 100 \\
\hline DRAK2 & STK17B & 93 & 85 & 74 & 23 & 100 & 86 & 73 & 85 & 100 \\
\hline DYRK1A & DYRK1A & 89 & 80 & 80 & 70 & 80 & 92 & 100 & 92 & 100 \\
\hline DYRK1B & DYRK1B & 85 & 85 & 84 & 95 & 87 & 72 & 84 & 89 & 68 \\
\hline DYRK2 & DYRK2 & 83 & 81 & 79 & 77 & 96 & 100 & 100 & 100 & 94 \\
\hline EGFR & EGFR & 75 & 84 & 82 & 100 & 100 & 67 & 100 & 97 & 97 \\
\hline EGFR(E746-A750del) & EGFR & 75 & 57 & 60 & 89 & 86 & 45 & 52 & 69 & 56 \\
\hline EGFR(G719C) & EGFR & 91 & 79 & 65 & 60 & 75 & 57 & 78 & 81 & 37 \\
\hline EGFR(G719S) & EGFR & 68 & 38 & 66 & 76 & 84 & 53 & 82 & 80 & 95 \\
\hline
\end{tabular}




\begin{tabular}{|c|c|c|c|c|c|c|c|c|c|}
\hline EGFR(L747-E749del, A750P) & EGFR & 66 & 78 & 63 & 82 & 94 & 61 & 100 & 100 \\
\hline EGFR(L747-S752del, P753S) & EGFR & 93 & 100 & 78 & 100 & 94 & 59 & 69 & 83 \\
\hline EGFR(L747-T751del,Sins) & EGFR & 90 & 56 & 52 & 80 & 85 & 50 & 97 & 72 \\
\hline EGFR(L858R) & EGFR & 68 & 73 & 62 & 78 & 97 & 47 & 91 & 93 \\
\hline EGFR(L858R,T790M) & EGFR & 95 & 77 & 81 & 51 & 56 & 37 & 90 & 89 \\
\hline EGFR(L861Q) & EGFR & 27 & 67 & 57 & 92 & 72 & 52 & 80 & 74 \\
\hline EGFR(S752-I759del) & EGFR & 87 & 67 & 69 & 84 & 76 & 36 & 77 & 46 \\
\hline EGFR(T790M) & EGFR & 98 & 100 & 98 & 64 & 64 & 44 & 86 & 73 \\
\hline EIF2AK1 & EIF2AK1 & 77 & 80 & 67 & 83 & 91 & 100 & 100 & 100 \\
\hline EPHA1 & EPHA1 & 83 & 91 & 83 & 24 & 98 & 40 & 100 & 100 \\
\hline EPHA2 & EPHA2 & 84 & 96 & 97 & 67 & 96 & 74 & 93 & 100 \\
\hline EPHA3 & EPHA3 & 92 & 88 & 91 & 39 & 99 & 93 & 98 & 88 \\
\hline EPHA4 & EPHA4 & 76 & 96 & 91 & 83 & 100 & 97 & 95 & 93 \\
\hline EPHA5 & EPHA5 & 89 & 92 & 89 & 65 & 100 & 76 & 77 & 78 \\
\hline EPHA6 & EPHA6 & 76 & 97 & 91 & 59 & 100 & 79 & 100 & 91 \\
\hline EPHA7 & EPHA7 & 99 & 100 & 97 & 40 & 100 & 92 & 94 & 94 \\
\hline EPHA8 & EPHA8 & 91 & 95 & 91 & 93 & 100 & 49 & 98 & 97 \\
\hline EPHB1 & EPHB1 & 84 & 69 & 71 & 28 & 100 & 90 & 95 & 90 \\
\hline EPHB2 & EPHB2 & 77 & 80 & 82 & 56 & 81 & 61 & 53 & 66 \\
\hline EPHB3 & EPHB3 & 81 & 100 & 87 & 94 & 100 & 87 & 98 & 91 \\
\hline EPHB4 & EPHB4 & 81 & 94 & 75 & 57 & 100 & 96 & 100 & 100 \\
\hline EPHB6 & EPHB6 & 70 & 42 & 33 & 6.6 & 49 & 4.8 & 100 & 93 \\
\hline ERBB2 & ERBB2 & 63 & 34 & 2.2 & 87 & 92 & 18 & 100 & 100 \\
\hline ERBB3 & ERBB3 & 100 & 100 & 87 & 45 & 78 & 53 & 100 & 96 \\
\hline ERBB4 & ERBB4 & 95 & 96 & 93 & 77 & 100 & 74 & 74 & 95 \\
\hline ERK1 & MAPK3 & 92 & 93 & 80 & 89 & 100 & 65 & 86 & 97 \\
\hline ERK2 & MAPK1 & 88 & 94 & 81 & 97 & 100 & 77 & 88 & 90 \\
\hline ERK3 & MAPK6 & 89 & 96 & 91 & 97 & 100 & 98 & 96 & 95 \\
\hline ERK4 & MAPK4 & 83 & 92 & 89 & 89 & 100 & 100 & 97 & 98 \\
\hline ERK5 & MAPK7 & 92 & 100 & 89 & 98 & 100 & 98 & 91 & 100 \\
\hline ERK8 & MAPK15 & 82 & 68 & 90 & 65 & 98 & 83 & 99 & 87 \\
\hline ERN1 & ERN1 & 80 & 87 & 86 & 59 & 70 & 91 & 100 & 100 \\
\hline FAK & PTK2 & 94 & 98 & 93 & 92 & 96 & 60 & 60 & 74 \\
\hline FER & FER & 79 & 98 & 91 & 91 & 97 & 91 & 98 & 96 \\
\hline FES & FES & 57 & 93 & 78 & 80 & 100 & 93 & 100 & 98 \\
\hline FGFR1 & FGFR1 & 85 & 72 & 39 & 11 & 74 & 10 & 77 & 90 \\
\hline FGFR2 & FGFR2 & 82 & 73 & 38 & 16 & 79 & 29 & 98 & 98 \\
\hline FGFR3 & FGFR3 & 91 & 91 & 60 & 18 & 84 & 36 & 84 & 100 \\
\hline FGFR3(G697C) & FGFR3 & 76 & 91 & 53 & 11 & 88 & 36 & 79 & 94 \\
\hline FGFR4 & FGFR4 & 89 & 82 & 49 & 37 & 100 & 37 & 70 & 92 \\
\hline FGR & FGR & 77 & 78 & 68 & 28 & 96 & 12 & 91 & 91 \\
\hline FLT1 & FLT1 & 98 & 53 & 67 & 34 & 95 & 24 & 87 & 96 \\
\hline FLT3 & FLT3 & 97 & 46 & 45 & 4.7 & 72 & 2.1 & 77 & 77 \\
\hline FLT3(D835H) & FLT3 & 80 & 64 & 61 & 7 & 39 & 15 & 94 & 82 \\
\hline FLT3(D835V) & FLT3 & 100 & 47 & 41 & 2.1 & 10 & 22 & 100 & 100 \\
\hline FLT3(D835Y) & FLT3 & 60 & 46 & 40 & 3.8 & 49 & 32 & 88 & 70 \\
\hline
\end{tabular}




\begin{tabular}{|c|c|c|c|c|c|c|c|c|c|c|}
\hline & & & & & & & & & & \\
\hline FLT3(ITD) & FLT3 & 89 & 34 & 58 & 9.3 & 56 & 23 & 82 & 92 & 98 \\
\hline FLT3(ITD,D835V) & FLT3 & 100 & 94 & 71 & 0.8 & 20 & 80 & 100 & 100 & 100 \\
\hline FLT3(ITD,F691L) & FLT3 & 96 & 92 & 84 & 2 & 25 & 100 & 100 & 100 & 76 \\
\hline FLT3(K663Q) & FLT3 & 90 & 43 & 45 & 6.5 & 80 & 13 & 74 & 87 & 96 \\
\hline FLT3(N841I) & FLT3 & 99 & 95 & 56 & 0 & 71 & 21 & 72 & 86 & 82 \\
\hline FLT3(R834Q) & FLT3 & 88 & 75 & 79 & 27 & 81 & 53 & 88 & 92 & 100 \\
\hline FLT3-autoinhibited & FLT3 & 64 & 47 & 46 & 26 & 72 & 5.6 & 100 & 94 & 95 \\
\hline FLT4 & FLT4 & 51 & 77 & 89 & 1.1 & 76 & 86 & 89 & 100 & 91 \\
\hline FRK & FRK & 80 & 57 & 58 & 78 & 95 & 41 & 71 & 100 & 92 \\
\hline FYN & FYN & 57 & 72 & 44 & 38 & 84 & 17 & 77 & 100 & 97 \\
\hline GAK & GAK & 19 & 7.8 & 6.2 & 9.6 & 24 & 4.5 & 86 & 54 & 20 \\
\hline GCN2(Kin.Dom.2,S808G) & EIF2AK4 & 99 & 88 & 81 & 100 & 100 & 96 & 98 & 100 & 100 \\
\hline GRK1 & GRK1 & 91 & 93 & 89 & 60 & 69 & 72 & 92 & 84 & 96 \\
\hline GRK2 & ADRBK1 & 89 & 93 & 100 & 40 & 100 & 100 & 97 & 100 & 99 \\
\hline GRK3 & ADRBK2 & 100 & 100 & 100 & 96 & 81 & 82 & 92 & 81 & 95 \\
\hline GRK4 & GRK4 & 78 & 80 & 100 & 83 & 67 & 88 & 87 & 100 & 71 \\
\hline GRK7 & GRK7 & 88 & 92 & 82 & 51 & 62 & 77 & 100 & 100 & 98 \\
\hline GSK3A & GSK3A & 100 & 85 & 97 & 87 & 60 & 76 & 92 & 70 & 93 \\
\hline GSK3B & GSK3B & 100 & 100 & 97 & 92 & 83 & 100 & 100 & 92 & 100 \\
\hline HASPIN & GSG2 & 73 & 53 & 11 & 33 & 48 & 13 & 100 & 100 & 97 \\
\hline HCK & HCK & 48 & 41 & 33 & 10 & 89 & 9.6 & 96 & 86 & 82 \\
\hline HIPK1 & HIPK1 & 76 & 62 & 59 & 58 & 83 & 43 & 78 & 59 & 82 \\
\hline HIPK2 & HIPK2 & 100 & 100 & 100 & 84 & 72 & 73 & 100 & 100 & 100 \\
\hline HIPK3 & HIPK3 & 100 & 97 & 92 & 91 & 78 & 59 & 100 & 88 & 100 \\
\hline HIPK4 & HIPK4 & 76 & 64 & 51 & 89 & 96 & 38 & 69 & 82 & 83 \\
\hline HPK1 & MAP4K1 & 98 & 93 & 60 & 38 & 99 & 68 & 98 & 100 & 100 \\
\hline HUNK & HUNK & 96 & 96 & 81 & 100 & 100 & 100 & 100 & 100 & 100 \\
\hline ICK & ICK & 100 & 100 & 98 & 85 & 71 & 100 & 100 & 100 & 92 \\
\hline IGF1R & IGF1R & 77 & 86 & 86 & 55 & 100 & 81 & 91 & 100 & 100 \\
\hline IKK-alpha & CHUK & 96 & 95 & 89 & 27 & 82 & 78 & 96 & 89 & 98 \\
\hline IKK-beta & IKBKB & 97 & 92 & 89 & 26 & 55 & 82 & 96 & 97 & 97 \\
\hline IKK-epsilon & IKBKE & 80 & 72 & 53 & 32 & 61 & 51 & 100 & 100 & 100 \\
\hline INSR & INSR & 80 & 84 & 98 & 24 & 69 & 27 & 89 & 74 & 80 \\
\hline INSRR & INSRR & 100 & 84 & 99 & 58 & 88 & 64 & 100 & 100 & 100 \\
\hline IRAK1 & IRAK1 & 100 & 97 & 88 & 20 & 66 & 36 & 100 & 83 & 100 \\
\hline IRAK3 & IRAK3 & 96 & 100 & 88 & 65 & 100 & 55 & 91 & 83 & 77 \\
\hline IRAK4 & IRAK4 & 100 & 99 & 90 & 28 & 67 & 84 & 100 & 93 & 97 \\
\hline ITK & ITK & 95 & 74 & 86 & 52 & 93 & 90 & 94 & 89 & 98 \\
\hline JAK1(JH1domain-catalytic) & JAK1 & 92 & 91 & 86 & 74 & 77 & 100 & 100 & 100 & 93 \\
\hline AK1(JH2domain-pseudokinase) & JAK1 & 13 & 12 & 20 & 0.2 & 0.25 & 45 & 1.9 & 3.2 & 15 \\
\hline JAK2(JH1domain-catalytic) & JAK2 & 94 & 94 & 87 & 0.95 & 15 & 76 & 79 & 74 & 93 \\
\hline JAK3(JH1domain-catalytic) & JAK3 & 96 & 88 & 99 & 5.3 & 1 & 87 & 23 & 17 & 84 \\
\hline JNK1 & MAPK8 & 100 & 85 & 47 & 17 & 57 & 66 & 86 & 89 & 89 \\
\hline JNK2 & МАРК9 & 74 & 60 & 17 & 64 & 57 & 52 & 97 & 95 & 91 \\
\hline JNK3 & MAPK10 & 81 & 77 & 31 & 36 & 60 & 67 & 100 & 100 & 96 \\
\hline KIT & $\mathrm{KIT}$ & 98 & 93 & 67 & 7.6 & 76 & 3.2 & 91 & 93 & 62 \\
\hline
\end{tabular}




\begin{tabular}{|c|c|c|c|c|c|c|c|c|c|c|}
\hline KIT(A829P) & KIT & 96 & 75 & 50 & 20 & 35 & 36 & 100 & 100 & 100 \\
\hline KIT(D816H) & KIT & 100 & 100 & 84 & 11 & 60 & 28 & 86 & 89 & 100 \\
\hline KIT(D816V) & KIT & 94 & 61 & 40 & 1.4 & 44 & 9.8 & 81 & 83 & 93 \\
\hline KIT(L576P) & KIT & 100 & 95 & 64 & 1.2 & 76 & 4.9 & 92 & 99 & 59 \\
\hline KIT(V559D) & KIT & 100 & 96 & 59 & 5.1 & 59 & 1.5 & 81 & 92 & 57 \\
\hline KIT(V559D,T670I) & KIT & 100 & 100 & 74 & 9.2 & 100 & 38 & 100 & 100 & 79 \\
\hline KIT(V559D,V654A) & KIT & 96 & 91 & 94 & 25 & 95 & 57 & 71 & 78 & 100 \\
\hline KIT-autoinhibited & KIT & 95 & 81 & 70 & 15 & 81 & 12 & 100 & 88 & 90 \\
\hline LATS1 & LATS1 & 56 & 91 & 76 & 100 & 100 & 90 & 100 & 99 & 100 \\
\hline LATS2 & LATS2 & 79 & 76 & 82 & 74 & 67 & 71 & 100 & 92 & 100 \\
\hline LCK & LCK & 76 & 29 & 15 & 21 & 54 & 2.8 & 87 & 78 & 74 \\
\hline LIMK1 & LIMK1 & 99 & 94 & 99 & 75 & 99 & 53 & 100 & 100 & 96 \\
\hline LIMK2 & LIMK2 & 89 & 96 & 87 & 87 & 97 & 79 & 97 & 89 & 80 \\
\hline LKB1 & STK11 & 73 & 89 & 87 & 90 & 91 & 81 & 100 & 97 & 64 \\
\hline LOK & STK10 & 80 & 70 & 68 & 4.3 & 100 & 35 & 99 & 100 & 97 \\
\hline LRRK2 & LRRK2 & 100 & 94 & 0 & 43 & 67 & 57 & 89 & 73 & 87 \\
\hline LRRK2(G2019S) & LRRK2 & 100 & 100 & 100 & 73 & 55 & 100 & 100 & 100 & 100 \\
\hline LTK & LTK & 75 & 79 & 75 & 54 & 100 & 44 & 88 & 89 & 100 \\
\hline LYN & LYN & 74 & 73 & 71 & 53 & 80 & 32 & 59 & 74 & 95 \\
\hline LZK & МАРЗК13 & 100 & 100 & 100 & 100 & 100 & 82 & 82 & 92 & 93 \\
\hline MAK & MAK & 97 & 76 & 52 & 95 & 100 & 70 & 95 & 91 & 100 \\
\hline MAP3K1 & MAP3K1 & 98 & 100 & 85 & 47 & 81 & 89 & 100 & 96 & 100 \\
\hline МАР3К15 & MАР3К15 & 100 & 100 & 88 & 39 & 60 & 90 & 100 & 96 & 100 \\
\hline МАР3К2 & МАР3К2 & 95 & 86 & 60 & 2.3 & 33 & 22 & 100 & 79 & 100 \\
\hline MAР3K3 & МАРЗКЗ & 84 & 66 & 51 & 4.2 & 45 & 11 & 92 & 77 & 87 \\
\hline MAP3K4 & MAP3K4 & 59 & 99 & 75 & 69 & 95 & 100 & 100 & 100 & 87 \\
\hline MAP4K2 & MAP4K2 & 88 & 94 & 93 & 21 & 66 & 62 & 100 & 100 & 100 \\
\hline MAP4K3 & MAP4K3 & 99 & 100 & 100 & 40 & 98 & 62 & 95 & 87 & 97 \\
\hline MAP4K4 & MAP4K4 & 89 & 97 & 99 & 71 & 100 & 84 & 85 & 95 & 100 \\
\hline MAP4K5 & MAP4K5 & 93 & 100 & 100 & 81 & 99 & 79 & 93 & 97 & 92 \\
\hline MAPKAPK2 & MAPKAPK2 & 93 & 100 & 100 & 100 & 100 & 88 & 99 & 100 & 95 \\
\hline MAPKAPK5 & MAPKAPK5 & 89 & 87 & 80 & 95 & 87 & 93 & 100 & 96 & 100 \\
\hline MARK1 & MARK1 & 92 & 96 & 91 & 77 & 91 & 57 & 56 & 65 & 100 \\
\hline MARK2 & MARK2 & 97 & 100 & 88 & 44 & 79 & 43 & 62 & 75 & 100 \\
\hline MARK3 & MARK3 & 93 & 95 & 100 & 89 & 100 & 87 & 96 & 100 & 100 \\
\hline MARK4 & MARK4 & 79 & 88 & 84 & 67 & 96 & 69 & 80 & 80 & 99 \\
\hline MAST1 & MAST1 & 100 & 100 & 100 & 94 & 63 & 55 & 100 & 95 & 68 \\
\hline MEK1 & MAР2K1 & 82 & 67 & 26 & 28 & 73 & 0.2 & 99 & 85 & 99 \\
\hline MEK2 & MAP2K2 & 67 & 72 & 35 & 35 & 84 & 0.55 & 87 & 89 & 100 \\
\hline MEK3 & МАР2К3 & 86 & 78 & 56 & 28 & 69 & 42 & 100 & 90 & 96 \\
\hline MEK4 & MAP2K4 & 74 & 66 & 30 & 31 & 59 & 38 & 100 & 96 & 91 \\
\hline MEK5 & MAP2K5 & 80 & 61 & 37 & 3.8 & 36 & 0.2 & 93 & 79 & 83 \\
\hline MEK6 & MAP2K6 & 81 & 100 & 85 & 67 & 87 & 65 & 77 & 87 & 91 \\
\hline MELK & MELK & 91 & 85 & 66 & 78 & 100 & 24 & 81 & 96 & 100 \\
\hline MERTK & MERTK & 78 & 53 & 60 & 15 & 93 & 65 & 91 & 96 & 71 \\
\hline MET & MET & 93 & 87 & 76 & 47 & 100 & 55 & 83 & 98 & 100 \\
\hline
\end{tabular}




\begin{tabular}{|c|c|c|c|c|c|c|c|c|c|c|}
\hline MET(M1250T) & MET & 100 & 100 & 100 & 84 & 100 & 72 & 99 & 100 & 87 \\
\hline MET(Y1235D) & MET & 82 & 77 & 72 & 59 & 94 & 40 & 77 & 83 & 94 \\
\hline MINK & MINK1 & 98 & 90 & 87 & 37 & 57 & 55 & 96 & 89 & 80 \\
\hline MKK7 & MAP2K7 & 100 & 100 & 100 & 96 & 68 & 100 & 100 & 100 & 100 \\
\hline MKNK1 & MKNK1 & 86 & 94 & 93 & 88 & 72 & 100 & 100 & 100 & 100 \\
\hline MKNK2 & MKNK2 & 73 & 64 & 55 & 54 & 66 & 18 & 95 & 92 & 75 \\
\hline MLCK & MYLK3 & 95 & 95 & 86 & 64 & 100 & 59 & 99 & 100 & 100 \\
\hline MLK1 & MAP3К9 & 95 & 89 & 81 & 12 & 96 & 59 & 72 & 92 & 100 \\
\hline MLK2 & MAP3K10 & 82 & 49 & 57 & 53 & 76 & 68 & 86 & 77 & 89 \\
\hline MLK3 & MAP3K11 & 77 & 92 & 71 & 21 & 89 & 46 & 74 & 83 & 98 \\
\hline MRCKA & CDC42BPA & 85 & 94 & 78 & 82 & 100 & 68 & 84 & 91 & 98 \\
\hline MRCKB & $\mathrm{CDC} 42 \mathrm{BPB}$ & 93 & 91 & 99 & 100 & 95 & 95 & 100 & 100 & 87 \\
\hline MST1 & STK4 & 81 & 87 & 87 & 64 & 91 & 54 & 96 & 94 & 100 \\
\hline MST1R & MST1R & 90 & 88 & 70 & 79 & 100 & 80 & 97 & 81 & 94 \\
\hline MST2 & STK3 & 100 & 100 & 78 & 66 & 73 & 71 & 90 & 85 & 78 \\
\hline MST3 & STK24 & 100 & 82 & 70 & 47 & 81 & 44 & 74 & 83 & 85 \\
\hline MST4 & MST4 & 100 & 100 & 87 & 64 & 71 & 52 & 100 & 95 & 100 \\
\hline MTOR & MTOR & 0 & 0 & 0 & 0 & 0 & 0 & 0 & 0 & 0 \\
\hline MUSK & MUSK & 100 & 87 & 100 & 96 & 99 & 100 & 100 & 100 & 100 \\
\hline MYLK & MYLK & 74 & 59 & 60 & 48 & 77 & 30 & 94 & 98 & 90 \\
\hline MYLK2 & MYLK2 & 100 & 41 & 96 & 97 & 100 & 93 & 81 & 96 & 100 \\
\hline MYLK4 & MYLK4 & 100 & 100 & 86 & 62 & 78 & 69 & 91 & 93 & 98 \\
\hline MYO3A & MYO3A & 94 & 94 & 88 & 93 & 93 & 31 & 88 & 92 & 92 \\
\hline MYO3B & МYO3B & 59 & 89 & 70 & 100 & 100 & 85 & 96 & 97 & 100 \\
\hline NDR1 & STK38 & 90 & 94 & 77 & 74 & 75 & 39 & 78 & 86 & 90 \\
\hline NDR2 & STK38L & 94 & 94 & 91 & 63 & 100 & 45 & 98 & 90 & 100 \\
\hline NEK1 & NEK1 & 84 & 89 & 81 & 81 & 100 & 95 & 61 & 100 & 84 \\
\hline NEK10 & NEK10 & 92 & 74 & 77 & 1.6 & 50 & 100 & 100 & 100 & 100 \\
\hline NEK11 & NEK11 & 100 & 99 & 100 & 92 & 87 & 92 & 85 & 100 & 100 \\
\hline NEK2 & NEK2 & 88 & 94 & 80 & 93 & 88 & 81 & 94 & 92 & 90 \\
\hline NEK3 & NEK3 & 87 & 81 & 80 & 75 & 67 & 67 & 93 & 75 & 83 \\
\hline NEK4 & NEK4 & 99 & 94 & 82 & 73 & 86 & 93 & 100 & 94 & 98 \\
\hline NEK5 & NEK5 & 85 & 90 & 82 & 74 & 94 & 100 & 100 & 89 & 76 \\
\hline NEK6 & NEK6 & 97 & 93 & 97 & 96 & 100 & 79 & 63 & 76 & 95 \\
\hline NEK7 & NEK7 & 77 & 86 & 71 & 75 & 100 & 87 & 91 & 89 & 100 \\
\hline NEK9 & NEK9 & 93 & 99 & 82 & 87 & 97 & 75 & 84 & 78 & 99 \\
\hline NIK & MAP3K14 & 89 & 80 & 93 & 25 & 81 & 85 & 76 & 81 & 100 \\
\hline NIM1 & MGC42105 & 99 & 100 & 91 & 88 & 77 & 80 & 100 & 96 & 94 \\
\hline NLK & NLK & 57 & 44 & 18 & 79 & 98 & 27 & 100 & 97 & 83 \\
\hline OSR1 & OXSR1 & 71 & 69 & 72 & 42 & 83 & 100 & 100 & 100 & 100 \\
\hline p38-alpha & MAPK14 & 97 & 100 & 84 & 96 & 93 & 82 & 86 & 99 & 100 \\
\hline p38-beta & MAPK11 & 70 & 83 & 82 & 83 & 99 & 98 & 78 & 100 & 100 \\
\hline p38-delta & MAPK13 & 100 & 85 & 80 & 96 & 100 & 64 & 100 & 73 & 92 \\
\hline p38-gamma & MAPK12 & 95 & 41 & 71 & 79 & 96 & 62 & 100 & 76 & 100 \\
\hline PAK1 & PAK1 & 83 & 90 & 87 & 76 & 88 & 53 & 86 & 81 & 96 \\
\hline PAK2 & PAK2 & 83 & 94 & 82 & 70 & 54 & 0 & 69 & 48 & 94 \\
\hline
\end{tabular}




\begin{tabular}{|c|c|c|c|c|c|c|c|c|c|c|}
\hline РАK3 & РАK3 & 76 & 100 & 92 & 86 & 100 & 60 & 92 & 93 & 99 \\
\hline PAK4 & PAK4 & 92 & 88 & 72 & 10 & 93 & 71 & 71 & 77 & 92 \\
\hline PAK6 & PAK6 & 91 & 91 & 84 & 17 & 94 & 72 & 81 & 89 & 83 \\
\hline PAK7 & PAK7 & 91 & 91 & 86 & 12 & 98 & 94 & 95 & 97 & 93 \\
\hline PCTK1 & CDK16 & 92 & 96 & 100 & 100 & 77 & 100 & 100 & 96 & 100 \\
\hline PCTK2 & CDK17 & 87 & 100 & 83 & 94 & 100 & 100 & 100 & 100 & 96 \\
\hline РСTK3 & CDK18 & 96 & 100 & 92 & 100 & 94 & 96 & 93 & 89 & 71 \\
\hline PDGFRA & PDGFRA & 61 & 43 & 23 & 15 & 40 & 12 & 100 & 95 & 99 \\
\hline PDGFRB & PDGFRB & 98 & 34 & 33 & 8.3 & 50 & 0.8 & 94 & 85 & 44 \\
\hline PDPK1 & PDPK1 & 89 & 97 & 87 & 49 & 94 & 58 & 92 & 72 & 89 \\
\hline PFCDPK1(P.falciparum) & CDPK1 & 93 & 68 & 29 & 46 & 88 & 2.4 & 97 & 87 & 92 \\
\hline PFPK5(P.falciparum) & MAL13P1.279 & 99 & 96 & 100 & 91 & 66 & 100 & 100 & 100 & 100 \\
\hline PFTAIRE2 & CDK15 & 79 & 98 & 80 & 96 & 94 & 88 & 97 & 82 & 97 \\
\hline PFTK1 & CDK14 & 99 & 100 & 100 & 97 & 90 & 84 & 96 & 90 & 71 \\
\hline PHKG1 & PHKG1 & 96 & 100 & 94 & 89 & 100 & 86 & 87 & 100 & 97 \\
\hline PHKG2 & PHKG2 & 97 & 88 & 73 & 72 & 96 & 62 & 76 & 86 & 80 \\
\hline РIK3С2B & РIК3С2B & 35 & 44 & 13 & 49 & 80 & 47 & 97 & 70 & 35 \\
\hline РIK3С2G & РIК3С2G & 2.4 & 0.7 & 2.7 & 16 & 66 & 41 & 100 & 20 & 7.4 \\
\hline PIK3CA & PIK3CA & 47 & 28 & 2.6 & 37 & 86 & 0 & 83 & 4.5 & 55 \\
\hline PIK3CA(C420R) & PIK3СA & 40 & 28 & 1.9 & 24 & 83 & 0 & 94 & 6.6 & 73 \\
\hline PIK3CA(E542K) & PIK3CA & 50 & 31 & 1.4 & 29 & 71 & 0.05 & 86 & 6.9 & 60 \\
\hline PIK3CA(E545A) & PIK3CA & 36 & 26 & 1.6 & 23 & 100 & 0 & 81 & 5.4 & 79 \\
\hline PIK3CA(E545K) & PIK3CA & 33 & 21 & 1.5 & 24 & 83 & 0 & 65 & 6.4 & 66 \\
\hline PIK3CA(H1047L) & PIK3CA & 27 & 10 & 0 & 7.7 & 51 & 0 & 100 & 0 & 27 \\
\hline PIK3CA(H1047Y) & PIKЗСА & 48 & 18 & 4.6 & 27 & 100 & 0 & 79 & 1.4 & 82 \\
\hline PIK3CA(1800L) & PIK3CA & 26 & 4.2 & 0 & 6.5 & 20 & 0 & 47 & 2.4 & 41 \\
\hline PIK3CA(M1043I) & PIK3CA & 44 & 36 & 2.5 & 21 & 74 & 0 & 100 & 0.7 & 40 \\
\hline PIK3CA(Q546K) & PIK3CA & 41 & 27 & 1.8 & 31 & 68 & 0 & 77 & 7.7 & 78 \\
\hline РIK3СB & PIK3CB & 47 & 39 & 3.1 & 43 & 66 & 0.5 & 100 & 9.6 & 73 \\
\hline PIK3CD & PIK3CD & 45 & 34 & 13 & 53 & 88 & 1.2 & 100 & 12 & 93 \\
\hline PIK3CG & PIK3CG & 2.3 & 0.75 & 0 & 0 & 28 & 0 & 75 & 0.05 & 3.7 \\
\hline PIK4CB & PI4KB & 2.8 & 2.2 & 2.3 & 1.6 & 0.55 & 5.5 & 25 & 3.8 & 1.3 \\
\hline PIKFYVE & PIKFYVE & 83 & 68 & 64 & 0.3 & 84 & 88 & 100 & 100 & 80 \\
\hline PIM1 & PIM1 & 100 & 100 & 94 & 100 & 99 & 93 & 80 & 85 & 91 \\
\hline PIM2 & PIM2 & 99 & 99 & 76 & 93 & 100 & 92 & 100 & 92 & 97 \\
\hline PIM3 & PIM3 & 93 & 95 & 75 & 76 & 96 & 85 & 92 & 81 & 91 \\
\hline PIP5K1A & PIP5K1A & 100 & 100 & 100 & 77 & 61 & 69 & 90 & 74 & 92 \\
\hline PIP5K1C & PIP5K1C & 100 & 100 & 72 & 62 & 32 & 72 & 87 & 87 & 70 \\
\hline PIP5K2B & PIP4K2B & 68 & 99 & 94 & 91 & 73 & 100 & 100 & 100 & 96 \\
\hline PIP5K2C & PIP4K2C & 38 & 27 & 20 & 5.9 & 62 & 62 & 100 & 100 & 30 \\
\hline PKAC-alpha & PRKACA & 96 & 100 & 100 & 100 & 99 & 19 & 94 & 86 & 100 \\
\hline PKAC-beta & PRKACB & 99 & 54 & 89 & 100 & 100 & 21 & 100 & 91 & 91 \\
\hline PKMYT1 & PKMYT1 & 89 & 78 & 91 & 90 & 93 & 88 & 84 & 95 & 100 \\
\hline PKN1 & PKN1 & 97 & 100 & 96 & 85 & 98 & 85 & 100 & 95 & 81 \\
\hline PKN2 & PKN2 & 100 & 89 & 92 & 66 & 93 & 99 & 87 & 91 & 87 \\
\hline PKNB(M.tuberculosis) & $\mathrm{pknB}$ & 99 & 87 & 93 & 9.3 & 70 & 28 & 90 & 71 & 78 \\
\hline
\end{tabular}




\begin{tabular}{|c|c|c|c|c|c|c|c|c|c|c|}
\hline PLK1 & PLK1 & 92 & 94 & 92 & 82 & 87 & 95 & 100 & 100 & 100 \\
\hline PLK2 & PLK2 & 71 & 79 & 73 & 31 & 100 & 97 & 100 & 100 & 100 \\
\hline PLK3 & PLK3 & 87 & 97 & 96 & 88 & 85 & 75 & 91 & 81 & 100 \\
\hline PLK4 & PLK4 & 100 & 100 & 96 & 25 & 84 & 30 & 68 & 81 & 91 \\
\hline PRKCD & PRKCD & 84 & 83 & 88 & 76 & 100 & 68 & 91 & 99 & 100 \\
\hline PRKCE & PRKCE & 93 & 85 & 77 & 73 & 91 & 35 & 100 & 100 & 79 \\
\hline PRKCH & PRKCH & 77 & 97 & 76 & 70 & 100 & 46 & 97 & 93 & 100 \\
\hline PRKCl & PRKCI & 83 & 48 & 54 & 68 & 92 & 36 & 88 & 48 & 88 \\
\hline PRKCQ & PRKCQ & 97 & 100 & 94 & 93 & 100 & 85 & 96 & 57 & 71 \\
\hline PRKD1 & PRKD1 & 97 & 43 & 33 & 100 & 100 & 70 & 91 & 100 & 91 \\
\hline PRKD2 & PRKD2 & 98 & 88 & 55 & 100 & 100 & 84 & 100 & 95 & 98 \\
\hline PRKD3 & PRKD3 & 100 & 78 & 43 & 100 & 100 & 84 & 96 & 83 & 97 \\
\hline PRKG1 & PRKG1 & 88 & 52 & 95 & 100 & 98 & 95 & 89 & 85 & 91 \\
\hline PRKG2 & PRKG2 & 81 & 64 & 71 & 38 & 83 & 88 & 100 & 85 & 100 \\
\hline PRKR & EIF2AK2 & 81 & 65 & 70 & 57 & 87 & 50 & 64 & 85 & 94 \\
\hline PRKX & PRKX & 100 & 95 & 92 & 98 & 100 & 93 & 99 & 87 & 84 \\
\hline PRP4 & PRPF4B & 100 & 88 & 83 & 77 & 100 & 96 & 98 & 98 & 79 \\
\hline PYK2 & PTK2B & 71 & 65 & 73 & 62 & 100 & 81 & 86 & 82 & 94 \\
\hline QSK & KIAA0999 & 100 & 99 & 92 & 90 & 74 & 79 & 100 & 99 & 100 \\
\hline RAF1 & RAF1 & 77 & 66 & 57 & 77 & 100 & 59 & 61 & 81 & 100 \\
\hline RET & RET & 92 & 88 & 53 & 1.9 & 61 & 3.8 & 70 & 78 & 90 \\
\hline RET(M918T) & RET & 83 & 37 & 46 & 1.2 & 61 & 3.7 & 100 & 95 & 80 \\
\hline RET(V804L) & RET & 96 & 45 & 92 & 19 & 67 & 91 & 99 & 99 & 83 \\
\hline RET(V804M) & RET & 98 & 94 & 86 & 22 & 74 & 61 & 88 & 83 & 94 \\
\hline RIOK1 & RIOK1 & 93 & 49 & 77 & 32 & 25 & 80 & 75 & 72 & 72 \\
\hline RIOK2 & RIOK2 & 100 & 100 & 82 & 55 & 75 & 90 & 100 & 100 & 100 \\
\hline RIOK3 & RIOK3 & 100 & 79 & 89 & 39 & 16 & 71 & 72 & 74 & 82 \\
\hline RIPK1 & RIPK1 & 94 & 94 & 94 & 90 & 96 & 87 & 92 & 92 & 90 \\
\hline RIPK2 & RIPK2 & 62 & 17 & 11 & 76 & 79 & 4.3 & 72 & 92 & 53 \\
\hline RIPK4 & RIPK4 & 100 & 98 & 90 & 4.7 & 92 & 72 & 100 & 100 & 100 \\
\hline RIPK5 & DSTYK & 56 & 70 & 57 & 27 & 90 & 61 & 100 & 96 & 66 \\
\hline ROCK1 & ROCK1 & 100 & 95 & 88 & 61 & 79 & 18 & 89 & 100 & 99 \\
\hline ROCK2 & ROCK2 & 87 & 82 & 84 & 69 & 84 & 22 & 99 & 100 & 95 \\
\hline ROS1 & ROS1 & 86 & 91 & 84 & 83 & 95 & 48 & 82 & 79 & 97 \\
\hline RPS6KA4(Kin.Dom.1-N-terminal) & RPS6KA4 & 97 & 42 & 93 & 100 & 100 & 77 & 89 & 85 & 82 \\
\hline RPS6KA4(Kin.Dom.2-C-terminal) & RPS6KA4 & 87 & 84 & 79 & 65 & 83 & 93 & 100 & 87 & 100 \\
\hline RPS6KA5(Kin.Dom.1-N-terminal) & RPS6KA5 & 75 & 100 & 86 & 100 & 100 & 73 & 96 & 100 & 100 \\
\hline RPS6KA5(Kin.Dom.2-C-terminal) & RPS6KA5 & 92 & 90 & 87 & 66 & 94 & 100 & 100 & 94 & 94 \\
\hline RSK1(Kin.Dom.1-N-terminal) & RPS6KA1 & 100 & 100 & 70 & 17 & 84 & 76 & 100 & 97 & 77 \\
\hline RSK1(Kin.Dom.2-C-terminal) & RPS6KA1 & 90 & 72 & 38 & 63 & 98 & 42 & 94 & 84 & 77 \\
\hline RSK2(Kin.Dom.1-N-terminal) & RPS6KA3 & 84 & 81 & 72 & 14 & 54 & 70 & 99 & 90 & 100 \\
\hline RSK2(Kin.Dom.2-C-terminal) & RPS6KA3 & 85 & 90 & 29 & 78 & 100 & 100 & 100 & 100 & 100 \\
\hline RSK3(Kin.Dom.1-N-terminal) & RPS6KA2 & 90 & 98 & 93 & 81 & 90 & 96 & 100 & 74 & 81 \\
\hline RSK3(Kin.Dom.2-C-terminal) & RPS6KA2 & 100 & 100 & 100 & 100 & 100 & 69 & 73 & 70 & 89 \\
\hline RSK4(Kin.Dom.1-N-terminal) & RPS6KA6 & 78 & 79 & 53 & 7.8 & 23 & 99 & 100 & 78 & 100 \\
\hline RSK4(Kin.Dom.2-C-terminal) & RPS6KA6 & 90 & 46 & 6.7 & 62 & 91 & 7 & 72 & 75 & 8 \\
\hline
\end{tabular}




\begin{tabular}{|c|c|c|c|c|c|c|c|c|c|c|}
\hline S6K1 & RPS6KB1 & 74 & 79 & 71 & 48 & 81 & 80 & 97 & 87 & 100 \\
\hline SBK1 & SBK1 & 92 & 75 & 82 & 68 & 75 & 95 & 100 & 100 & 94 \\
\hline SGK & SGK1 & 100 & 100 & 100 & 89 & 65 & 80 & 100 & 86 & 100 \\
\hline SgK110 & SgK110 & 73 & 100 & 73 & 100 & 100 & 100 & 100 & 100 & 81 \\
\hline SGK2 & SGK2 & 100 & 100 & 100 & 86 & 82 & 99 & 100 & 96 & 100 \\
\hline SGK3 & SGK3 & 61 & 64 & 67 & 45 & 87 & 96 & 96 & 93 & 93 \\
\hline SIK & SIK1 & 98 & 93 & 88 & 48 & 100 & 50 & 74 & 80 & 96 \\
\hline SIK2 & SIK2 & 100 & 94 & 100 & 41 & 92 & 66 & 100 & 91 & 81 \\
\hline SLK & SLK & 94 & 100 & 76 & 7.7 & 93 & 31 & 89 & 92 & 98 \\
\hline SNARK & NUAK2 & 67 & 70 & 60 & 4.8 & 26 & 65 & 100 & 91 & 97 \\
\hline SNRK & SNRK & 86 & 72 & 75 & 80 & 96 & 100 & 100 & 100 & 97 \\
\hline SRC & SRC & 79 & 76 & 74 & 6.5 & 71 & 19 & 89 & 74 & 89 \\
\hline SRMS & SRMS & 83 & 80 & 71 & 43 & 81 & 42 & 100 & 96 & 87 \\
\hline SRPK1 & SRPK1 & 100 & 83 & 77 & 17 & 24 & 78 & 74 & 74 & 85 \\
\hline SRPK2 & SRPK2 & 84 & 65 & 89 & 97 & 100 & 100 & 78 & 100 & 100 \\
\hline SRPK3 & SRPK3 & 78 & 72 & 72 & 73 & 80 & 89 & 86 & 99 & 71 \\
\hline STK16 & STK16 & 76 & 79 & 69 & 7 & 90 & 3.1 & 84 & 90 & 81 \\
\hline STK33 & STK33 & 99 & 100 & 99 & 97 & 100 & 92 & 94 & 100 & 90 \\
\hline STK35 & STK35 & 100 & 100 & 63 & 56 & 99 & 6.3 & 98 & 90 & 100 \\
\hline STK36 & STK36 & 80 & 73 & 28 & 90 & 90 & 79 & 84 & 85 & 85 \\
\hline STK39 & STK39 & 100 & 100 & 90 & 65 & 64 & 65 & 100 & 85 & 94 \\
\hline SYK & SYK & 90 & 88 & 72 & 33 & 73 & 76 & 79 & 67 & 82 \\
\hline TAK1 & MAP3K7 & 67 & 72 & 46 & 4 & 56 & 71 & 100 & 88 & 100 \\
\hline TAOK1 & TAOK1 & 85 & 74 & 35 & 96 & 72 & 10 & 100 & 100 & 87 \\
\hline TAOK2 & TAOK2 & 70 & 83 & 81 & 99 & 90 & 5.6 & 90 & 91 & 96 \\
\hline TAOK3 & TAOK3 & 81 & 94 & 90 & 100 & 81 & 71 & 100 & 100 & 99 \\
\hline TBK1 & TBK1 & 84 & 78 & 84 & 18 & 81 & 66 & 66 & 69 & 93 \\
\hline TEC & TEC & 95 & 94 & 93 & 40 & 100 & 91 & 91 & 94 & 100 \\
\hline TESK1 & TESK1 & 83 & 97 & 63 & 61 & 100 & 8.9 & 89 & 84 & 89 \\
\hline TGFBR1 & TGFBR1 & 91 & 94 & 72 & 81 & 100 & 7.8 & 56 & 85 & 69 \\
\hline TGFBR2 & TGFBR2 & 89 & 5.9 & 48 & 32 & 100 & 14 & 82 & 100 & 38 \\
\hline TIE1 & TIE1 & 100 & 88 & 44 & 73 & 94 & 51 & 100 & 100 & 93 \\
\hline TIE2 & TEK & 92 & 36 & 51 & 68 & 94 & 40 & 80 & 98 & 100 \\
\hline TLK1 & TLK1 & 98 & 96 & 83 & 85 & 91 & 76 & 79 & 80 & 75 \\
\hline TLK2 & TLK2 & 83 & 86 & 82 & 75 & 98 & 87 & 79 & 86 & 95 \\
\hline TNIK & TNIK & 92 & 86 & 84 & 18 & 64 & 46 & 77 & 76 & 84 \\
\hline TNK1 & TNK1 & 100 & 100 & 89 & 47 & 97 & 37 & 95 & 90 & 90 \\
\hline TNK2 & TNK2 & 84 & 81 & 76 & 51 & 99 & 83 & 100 & 100 & 90 \\
\hline TNNI3K & TNNI3K & 94 & 100 & 75 & 38 & 100 & 53 & 71 & 94 & 93 \\
\hline TRKA & NTRK1 & 97 & 73 & 45 & 7.5 & 38 & 3.9 & 81 & 74 & 100 \\
\hline TRKB & NTRK2 & 100 & 100 & 65 & 12 & 62 & 12 & 95 & 83 & 100 \\
\hline TRKC & NTRK3 & 100 & 100 & 87 & 29 & 38 & 12 & 100 & 100 & 100 \\
\hline TRPM6 & TRPM6 & 98 & 83 & 57 & 54 & 77 & 89 & 96 & 91 & 100 \\
\hline TSSK1B & TSSK1B & 100 & 92 & 100 & 96 & 100 & 93 & 95 & 100 & 100 \\
\hline TSSK3 & TSSK3 & 100 & 91 & 97 & 73 & 90 & 86 & 98 & 94 & 93 \\
\hline TTK & TTK & 86 & 57 & 4.9 & 47 & 100 & 15 & 81 & 68 & 62 \\
\hline
\end{tabular}




\begin{tabular}{|c|c|c|c|c|c|c|c|c|c|}
\hline TXK & TXK & 75 & 83 & 80 & 31 & 93 & 36 & 100 & 100 \\
\hline TYK2(JH1domain-catalytic) & TYK2 & 100 & 100 & 100 & 8.1 & 11 & 93 & 70 & 68 \\
\hline TYK2(JH2domain-pseudokinase) & TYK2 & 59 & 51 & 46 & 1.6 & 27 & 57 & 84 & 82 \\
\hline TYRO3 & TYRO3 & 51 & 92 & 41 & 51 & 84 & 51 & 100 & 100 \\
\hline ULK1 & ULK1 & 69 & 71 & 79 & 72 & 76 & 100 & 100 & 100 \\
\hline ULK2 & ULK2 & 99 & 100 & 92 & 72 & 75 & 77 & 96 & 91 \\
\hline ULK3 & ULK3 & 90 & 94 & 71 & 8.2 & 69 & 84 & 100 & 96 \\
\hline VEGFR2 & KDR & 73 & 85 & 74 & 14 & 75 & 43 & 100 & 97 \\
\hline VPS34 & РІКЗСЗ & 47 & 65 & 75 & 71 & 69 & 95 & 100 & 74 \\
\hline VRK2 & VRK2 & 74 & 96 & 97 & 36 & 3.8 & 100 & 100 & 100 \\
\hline WEE1 & WEE1 & 90 & 97 & 99 & 100 & 100 & 62 & 72 & 81 \\
\hline WEE2 & WEE2 & 82 & 62 & 66 & 77 & 95 & 87 & 94 & 81 \\
\hline WNK1 & WNK1 & 84 & 76 & 4.9 & 79 & 82 & 1.6 & 100 & 92 \\
\hline WNK2 & WNK2 & 73 & 71 & 0 & 100 & 63 & 16 & 100 & 100 \\
\hline WNK3 & WNK3 & 90 & 83 & 1.6 & 83 & 91 & 16 & 100 & 92 \\
\hline WNK4 & WNK4 & 100 & 100 & 11 & 100 & 97 & 4.8 & 100 & 100 \\
\hline YANK1 & STK32A & 71 & 63 & 55 & 28 & 82 & 99 & 100 & 99 \\
\hline YANK2 & STK32B & 77 & 98 & 87 & 88 & 100 & 79 & 85 & 93 \\
\hline YANK3 & STK32C & 82 & 93 & 70 & 70 & 100 & 81 & 89 & 100 \\
\hline YES & YES1 & 75 & 82 & 58 & 27 & 98 & 43 & 100 & 100 \\
\hline YSK1 & STK25 & 79 & 97 & 81 & 70 & 96 & 41 & 100 & 99 \\
\hline YSK4 & МАРЗК19 & 90 & 40 & 28 & 0.25 & 29 & 35 & 91 & 96 \\
\hline ZAK & ZAK & 78 & 87 & 90 & 44 & 100 & 69 & 100 & 99 \\
\hline ZAP70 & ZAP70 & 95 & 99 & 100 & 61 & 73 & 94 & 100 & 93 \\
\hline
\end{tabular}




\section{General synthetic methods}

${ }^{1} \mathrm{H}$ NMR spectra were recorded on a BRUKER $400 \mathrm{MHz}$ spectrometer. Chemical shifts are reported as $\delta$ values downfield from internal TMS in appropriate organic solutions. The abbreviations used for explaining the multiplicities were as follows: $s=$ singlet, $d=$ doublet, $t=$ triplet, $q=$ quartet, $m=$ multiplet, $b r=$ broad. High resolution mass (ESI HRMS) was recorded on a Thermofisher Q Exactive ${ }^{\mathrm{TM}}$ Hybrid Quadrupole-Orbitrap ${ }^{\mathrm{TM}}$ Mass Spectrometer. The relative purity and the mass of the products were confirmed by LC/MS (220 nm to $420 \mathrm{~nm}$ ) on a Waters acquity uplc photodiode array detector system using the following conditions: Column, BEH C18 50*2.1 mm; $1.8 \mu \mathrm{m}$; Solvent A, water $0.1 \%$ formic acid or water ammonium carbonate $2 \mathrm{~g} / \mathrm{l}$; Solvent $\mathrm{B}, \mathrm{CH} 3 \mathrm{CN}$; flow rate, $0.8 \mathrm{ml} / \mathrm{min}$; run time, 2.2 min; gradient, from 5 to $95 \%$ solvent B; mass detector, Waters SQ detector. All compounds were purified by LC/MS on a waters Autopurification system using the following conditions : Column, Xbridge C18 150*30mm, $5 \mu \mathrm{m}$; Solvent A, water $0.1 \%$ formic acid or water ammonium carbonate 2 $\mathrm{g} / \mathrm{l}$; Solvent $\mathrm{B}, \mathrm{CH} 3 \mathrm{CN}$; flow rate, $50 \mathrm{ml} / \mathrm{min}$; run time, 10 or $15 \mathrm{~min}$; with adapted isocratic elution mode; mass detector, Waters ZQ detector.

\section{Abbreviations}

$\begin{array}{llll}\mathrm{AcOH} & \text { acetic acid } & \mathrm{EtOAc} & \text { ethyl acetate } \\ \mathrm{NH}_{3} & \text { ammonia } & \mathrm{Et}_{2} \mathrm{O} & \text { diethyl ether } \\ \mathrm{HCl} & \text { hydrochloric acid } & \mathrm{THF} & \text { tetrahydrofuran } \\ \mathrm{MeOH} & \text { methanol } & \mathrm{DMSO} & \text { dimethyl sulfoxide } \\ \mathrm{MeCN} & \text { acetonitrile } & \mathrm{HCl} & \text { hydrochloric acid } \\ \mathrm{Na}_{2} \mathrm{SO}_{4} \text { sodium sulfate } & \mathrm{DMF} & \mathrm{N}, \mathrm{N} \text {-dimethylformamide }\end{array}$

HPLC high performance liquid chromatography

\section{Preparation of compounds shown in Table 1. $R_{1}$ exploration}

Preparation of 5-(4-Amino-1-isopropyl-1H-pyrazolo[3,4-d]pyrimidin-3-yl)benzo[d]oxazol-2-amine (1)

Compound 1 was prepared by employing the following sequence:<smiles>Nc1ncnc2[nH]ncc12</smiles><smiles>Nc1ncnc2[nH]nc(Br)c12</smiles><smiles>CC(C)C</smiles><smiles>CC(C)n1nc(Br)c2c(N)ncnc21</smiles><smiles>CC1(C)OB(c2ccc3oc(N)nc3c2)OC1(C)C</smiles><smiles>CC(I)n1nc(-c2ccc3oc(N)nc3c2)c2c(N)ncnc21</smiles>

\section{3-Bromo-1-isopropyl-1H-pyrazolo[3,4-d]pyrimidin-4-amine}


$\mathrm{N}$-Bromosuccinimide $(6.92 \mathrm{~g}, 38.9 \mathrm{mmol}, 1.05 \mathrm{eq}$.) was added to a suspension of $1 \mathrm{H}$-pyrazolo[3,4d]pyrimidin-4-ylamine $(5.00 \mathrm{~g}, 37.0 \mathrm{mmol}, 1.00$ eq.) in DMF $(50 \mathrm{ml})$ and the reaction mixture was heated at $60^{\circ} \mathrm{C}$ for 3 hours, cooled to room temperature and the solid was collected by filtration, washed with diethyl ether and dried to a constant weight to afford the title compound (7.92 $\mathrm{g}$, quant.) as a beige solid: $\operatorname{LCMS}\left(t_{\mathrm{R}}=0.70 \mathrm{~min}\right.$., purity= $\left.96.7 \%\right), \mathrm{ESI}+\mathrm{m} / \mathrm{z} 214,216(\mathrm{M}+\mathrm{H})^{+}$. The compound was directly engaged in the next step without further purification.

2-lodopropane $(5.54 \mathrm{ml}, 55.5 \mathrm{mmol}, 1.50$ eq.) was added to a stirred solution of 3-bromo- $1 \mathrm{H}$ pyrazolo[3,4-d]pyrimidin-4-ylamine (7.92 g, $37.0 \mathrm{mmol}, 1.00 \mathrm{eq}$.) and cesium carbonate $(36.17 \mathrm{~g}, 110$ $\mathrm{mmol}, 3.00$ eq.) in DMF $(30.0 \mathrm{ml})$. The reaction mixture was stirred at room temperature for $16 \mathrm{~h}$, filtered and the filtrate was purified by flash chromatography (silica gel, DCM-MeOH (0-20\%). The fractions were evaporated and the residue crystallised from heptane / EtOAc. The solid was collected by filtration and dried to a constant weight to afford the title compound $(5.75 \mathrm{~g}, 61 \%)$ as a beige solid: LCMS ( $t_{R}=0.79$ min., purity= 99.8\%), ESI+ m/z 256, $257(\mathrm{M}+\mathrm{H})^{+} ;{ }^{1} \mathrm{H}$ NMR $\left(400 \mathrm{MHz}, \mathrm{DMSO}-d_{6}\right) \delta$ 1.42-1.44 (d, $J=6.7 \mathrm{~Hz}, 6 \mathrm{H}), 4.94-5.01(\mathrm{q}, J=6.7 \mathrm{~Hz}, 1 \mathrm{H}), 8.20(\mathrm{~s}, 1 \mathrm{H})$.

\section{5-(4-Amino-1-isopropyl-1H-pyrazolo[3,4-d]pyrimidin-3-yl)benzo[d]oxazol-2-amine (1)}

Tetrakis(triphenylphosphine)palladium(0) $(2.08 \mathrm{~g}, 1.80 \mathrm{mmol}, 0.08 \mathrm{eq}$.) was added to a mixture of 3bromo-1-isopropyl-1H-pyrazolo[3,4-d]pyrimidin-4-ylamine (5.75 g, $22.5 \mathrm{mmol}, 1.00$ eq.), 5-(4,4,5,5tetramethyl-1,3,2-dioxaborolan-2-yl)benzo[d]oxazol-2-amine $(7.59 \mathrm{~g}, 29.2 \mathrm{mmol}, 1.30 \mathrm{eq}$.$) and$ sodium carbonate $(11.9 \mathrm{~g}, 110 \mathrm{mmol}, 5.00$ eq.) in 1,4-dioxane $(86.3 \mathrm{~mL})$ et water $(28.8 \mathrm{~mL})$ : The reaction mixture was heated at $110{ }^{\circ} \mathrm{C}$ for $2 \mathrm{~h} 45 \mathrm{~min}$, cooled to room temperature and filtered through a pad of Celite. The filtrate was concentrated and the residue was triturated with DCM. The solid was recuperated by filtration, washed with EtOAc and dried to a constant weight to afford the title compound $(1,6.42 \mathrm{~g}, 92 \%)$ as a pale pink solid that was used without further purification: ${ }^{1} \mathrm{H}$ NMR $\left(400 \mathrm{MHz}, \mathrm{DMSO}-d_{6}\right) \delta 1.49(\mathrm{~d}, J=6.7 \mathrm{~Hz}, 6 \mathrm{H}), 5.05(\mathrm{p}, J=6.7 \mathrm{~Hz}, 1 \mathrm{H}), 7.24(\mathrm{dd}, J=8.2,1.8 \mathrm{~Hz}$, $1 \mathrm{H}), 7.41(\mathrm{~d}, J=1.7 \mathrm{~Hz}, 1 \mathrm{H}), 7.46(\mathrm{~d}, J=8.1 \mathrm{~Hz}, 1 \mathrm{H}), 7.52(\mathrm{~s}, 2 \mathrm{H}), 8.23(\mathrm{~s}, 1 \mathrm{H})$.

HRMS (ESI) calculated for $\mathrm{C}_{15} \mathrm{H}_{15} \mathrm{~N}_{7} \mathrm{O}[\mathrm{M}+\mathrm{H}]^{+} 310.1411$, found 310.14096 .

Preparation of :

- 5-(6-Amino-4-chloro-1-isopropyl-1H-pyrazolo[3,4-d]pyrimidin-3-yl)benzo[d]oxazol-2amine (3e)

- 5-(6-Amino-1-isopropyl-4-methyl-1 H-pyrazolo[3,4-d]pyrimidin-3-yl)benzo[d]oxazol-2amine (3a)

- 5-(6-Amino-1-butyl-4-chloro-1 H-pyrazolo[3,4-d]pyrimidin-3-yl)benzo[d]oxazol-2-amine (4b)

- 5-(6-Amino-1-butyl-4-methyl-1H-pyrazolo[3,4-d]pyrimidin-3-yl)benzo[d]oxazol-2-amine (4a)

- 5-(6-Amino-4-ethyl-1-isopropyl-1H-pyrazolo[3,4-d]pyrimidin-3-yl)benzo[d]oxazol-2amine (3b)

Compound $\mathbf{3 e}, \mathbf{3 a}, \mathbf{4 a}$ and $\mathbf{3 b}$ were prepared by employing the following sequence: 

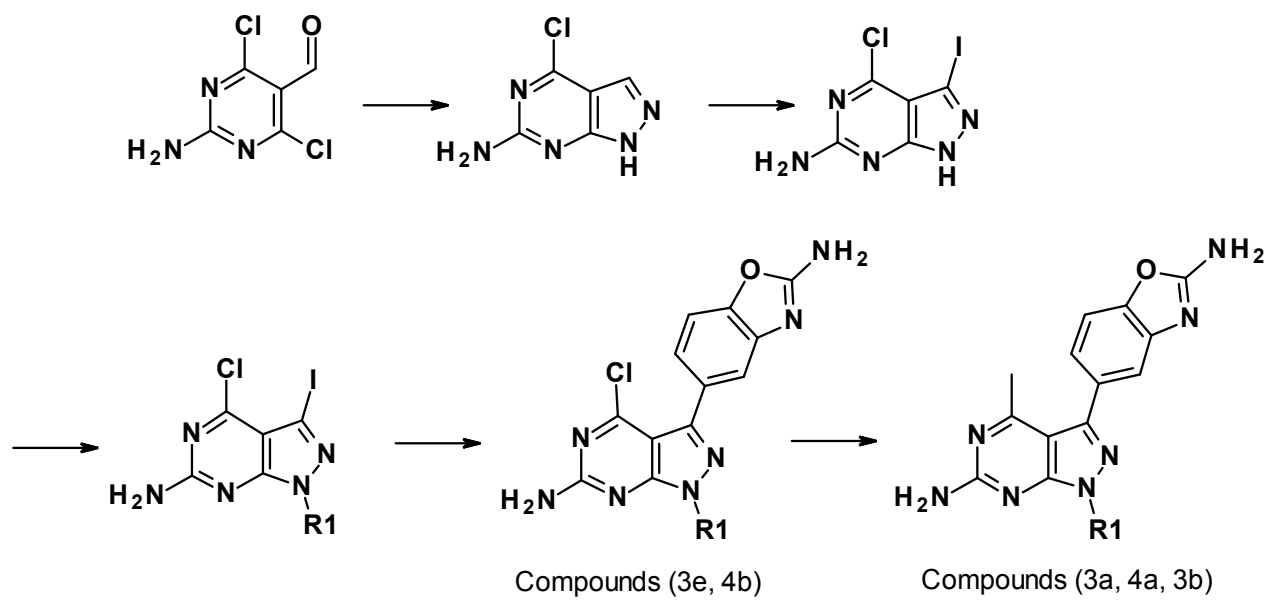

\section{4-Chloro-1H-pyrazolo[3,4-d]pyrimidin-6-amine}

2-Amino-4,6-dichloropyrimidine-5-carbaldehyde $(30.0 \mathrm{~g}, 156 \mathrm{mmol}, 1.0$ equiv) and triethylamine ( $30.5 \mathrm{~mL}, 219 \mathrm{mmol}, 1.15$ equiv) were dissolved into a mixture of $\mathrm{THF} / \mathrm{H}_{2} \mathrm{O} 3.5 / 1$. Hydrazine solution $98 \mathrm{wt} \%$ in water $(9.10 \mathrm{~mL}, 188 \mathrm{mmol}, 1.0$ equiv) was added dropwise over a period of $20 \mathrm{~min}$. The mixture was stirred at $60{ }^{\circ} \mathrm{C}$ for $1 \mathrm{~h} 30 \mathrm{~min}$ and left at room temperature overnight affording a heterogeneous mixture. After filtration of the orange precipitate, the filtrate was concentrated in under vacuum to give the desired product $(15.2 \mathrm{~g}, 89.6 \mathrm{mmol}, 57 \%)$ that was used without further purification: LCMS $\left(t_{\mathrm{R}}=0.78 \mathrm{~min}\right.$., purity= $\left.100 \%\right), \mathrm{ESI}+\mathrm{m} / \mathrm{z} 170(\mathrm{M}+\mathrm{H})^{+} ;{ }^{1} \mathrm{H}$ NMR $\left(400 \mathrm{MHz}, \mathrm{DMSO}-d_{6}\right) \delta$ 7.15 (br s, 2H), $7.96(\mathrm{~s}, 1 \mathrm{H}), 13.25(\mathrm{~s}, 1 \mathrm{H})$.

\section{4-Chloro-3-iodo-1H-pyrazolo[3,4-d]pyrimidin-6-amine}

To a solution of 4-chloro- $1 \mathrm{H}$-pyrazolo[3,4-d]pyrimidin-6-amine $(7.0 \mathrm{~g}, 41.28 \mathrm{mmol}, 1.0$ equiv) in DMF (105 mL, $0.4 \mathrm{M})$ was added $\mathrm{N}$-iodosuccinimide $(18.57 \mathrm{~g}, 82.56 \mathrm{mmol}, 2.0$ equiv) at room temperature. The mixture was heated at $80^{\circ} \mathrm{C}$ until full conversion by HPLC-MS of the starting material and cooled down to $25^{\circ} \mathrm{C}$ to be transferred over a $1 \mathrm{~L}$ solution of cold water. The precipitate formed was filtered and dried to obtain the desired product as a yellow solid $(12.0 \mathrm{~g}, 98 \%)$ : LCMS $\left(t_{\mathrm{R}}=1.08 \mathrm{~min}\right.$., purity= 99\%), ESI+ m/z $296(\mathrm{M}+\mathrm{H})^{+} ;{ }^{1} \mathrm{H}$ NMR (400 MHz, DMSO-d 6 ) $\delta$ 7.31-7.48 (br s, 2H), $13.51(\mathrm{~s}, 1 \mathrm{H})$.

\section{Generic alkylation procedure to afford 4-amino-3-iodo-1-alkyl-1H-pyrazolo[3,4-d]pyrimidin-6- amine analogues}

To a solution of 4-chloro-3-iodo- $1 \mathrm{H}$-pyrazolo[3,4-d]pyrimidin-6-amine in DMF (0.34 M) was added cesium carbonate (1.05 equiv) and the desired alkylation reagent ( $R_{1}-X, 1.05$ equiv.). The mixture was stirred at room temperature until completion of the reaction by HPLC-MS and then diluted with EtOAc and water. The separated aqueous phase was extracted with EtOAc and the combined organic layers were washed with water, brine and dried over $\mathrm{Na}_{2} \mathrm{SO}_{4}$. After filtration, the solvent was removed under reduced pressure and the residue was purified by silica gel column chromatography to yield desired alkylated derivative. 
<smiles>CC(C)n1nc(-c2ccc3oc(N)nc3c2)c2c(Cl)nc(N)nc21</smiles>

\section{5-(6-Amino-4-chloro-1-isopropyl-1H-pyrazolo[3,4-d]pyrimidin-3-yl)benzo[d]oxazol-2-amine (3e)}

To a stirred suspension of 3-iodo-4-chloro-1H-pyrazolo[3,4-d]pyrimidin-6-ylamine (1.00 g, $3.64 \mathrm{mmol}$, 1.00 eq.) and cesium carbonate $(2.37 \mathrm{~g} ; 7.27 \mathrm{mmol} ; 2.00$ eq.) in DMF (10 ml), was added 2iodopropane $(0.38 \mathrm{ml} ; 3.82 \mathrm{mmol}, 1.05$ eq.) and the reaction mixture was stirred for $3 \mathrm{~h}$ and 30 minutes at room temperature. Water was added and the reaction mixture was extracted into EtOAc. The organic phases were washes with water, dried over $\mathrm{MgSO}_{4}$ and concentrated to dryness. The residue was purified by flash chromatography (silica gel, heptane/ EtOAc 1:1) to afford the title compound $(880 \mathrm{mg}, 76 \%)$ : LCMS $\left(t_{\mathrm{R}}=0.97 \mathrm{~min}\right.$., purity= 95\%), ESI+ m/z $318(\mathrm{M}+\mathrm{H})^{+} ;{ }^{1} \mathrm{H}$ NMR $(400$ $\left.\mathrm{MHz}, \mathrm{DMSO}-d_{6}\right) \delta 1.38(\mathrm{~d}, J=6.6 \mathrm{~Hz}, 6 \mathrm{H}), 2.63(\mathrm{~s}, 3 \mathrm{H}), 4.80$ (hept, $\left.J=6.6 \mathrm{~Hz}, 1 \mathrm{H}\right), 6.91(\mathrm{~s}, 2 \mathrm{H})$.

In a microwave tube, was added 4-chloro-3-iodo-1-isopropyl-1H-pyrazolo[3,4-d]pyrimidin-6-ylamine (0.50 g, $1.48 \mathrm{mmol}, 1.00$ eq.) and 5-(4,4,5,5-tetramethyl-1,3,2-dioxaborolan-2-yl)benzo[d]oxazol-2amine $(0.58 \mathrm{~g}, 2.22 \mathrm{mmol}, 1.50$ eq.) to a mixture of 1,4-dioxane $(5.28 \mathrm{ml})$ and a $2.0 \mathrm{M}$ aqueous solution of potassium carbonate $(2.22 \mathrm{ml}, 4.44 \mathrm{mmol}, 3.00$ eq.). The reaction mixture was degassed and purged with argon. 1,1'-Bis(diphenylphosphino)ferrocenepalladium(II) dichloride, dichloromethane $(121 \mathrm{mg}, 0.15 \mathrm{mmol}, 0.10$ eq.) was added rapidly and the reaction mixture was heated at $100{ }^{\circ} \mathrm{C}$ for 60 minutes, cooled to room temperature and EtOAc was added. The reaction mixture was filtered, concentrated to dryness and purified by mass-triggered preparative LCMS (acidic conditions) to afford the title compound (3e, $210 \mathrm{mg}, 41 \%)$ : LCMS $\left(t_{\mathrm{R}}=1.03 \mathrm{~min}\right.$., purity= 97\%), $\mathrm{ESI}+\mathrm{m} / \mathrm{z} 344(\mathrm{M}+\mathrm{H})^{+} ;{ }^{1} \mathrm{H} \mathrm{NMR}\left(\mathrm{DMSO}-d_{6}\right) \delta 1.47(\mathrm{~d}, J=6.7 \mathrm{~Hz}, 6 \mathrm{H}), 4.91(\mathrm{~h}, \mathrm{~J}=6.7 \mathrm{~Hz}, 1 \mathrm{H}), 7.22-7.32$ $(\mathrm{m}, 3 \mathrm{H}), 7.41(\mathrm{~d}, J=8.2 \mathrm{~Hz}, 1 \mathrm{H}), 7.44-7.50(\mathrm{~m}, 3 \mathrm{H})$.

HRMS (ESI) calculated for $\mathrm{C}_{16} \mathrm{H}_{14} \mathrm{ClN}_{7} \mathrm{O}[\mathrm{M}+\mathrm{H}]^{+} 344.1021$, found 344.1019 .<smiles>Cc1nc(N)nc2c1c(-c1ccc3oc(N)nc3c1)nn2C(C)C</smiles>

\section{5-(6-Amino-1-isopropyl-4-methyl-1H-pyrazolo[3,4- $d]$ pyrimidin-3-yl)benzo[d]oxazol-2-amine (3a)}

5-(6-Amino-4-chloro-1-isopropyl-1H-pyrazolo[3,4-d]pyrimidin-3-yl)benzo[d]oxazol-2-amine (3e, 50.0 $\mathrm{mg}, 0.15 \mathrm{mmol}, 1.00$ eq.) was dissolved in THF $(250 \mu \mathrm{l})$ and bis(tri-t-butylphosphine)palladium(0) (14.9 mg, $0.03 \mathrm{mmol}, 0.20$ eq.) was added at $0{ }^{\circ} \mathrm{C}$. The reaction mixture was degassed and purged with argon and $1 \mathrm{M}$ solution of dimethylzinc in heptane $(436 \mu \mathrm{l}, 0.44 \mathrm{mmol}, 3.00$ eq.) was added 
keeping the temperature at $0{ }^{\circ} \mathrm{C}$. The reaction mixture was stirred at room temperature overnight, quenched with a saturated aqueous solution of ammonium chloride and extracted with EtOAc. The organic phase was washed with brine, dried over $\mathrm{MgSO}_{4}$ and concentrated to dryness. The residue was purified by mass-triggered preparative HPLC (acidic method) to afford the title compound (3a, $14.3 \mathrm{mg}, 30 \%)$ as a beige solid: LCMS $\left(t_{\mathrm{R}}=0.92 \mathrm{~min}\right.$., purity=97\%), $\mathrm{ESI}+\mathrm{m} / \mathrm{z} 324(\mathrm{M}+\mathrm{H})^{+} ;{ }^{1} \mathrm{H}$ NMR $(400$ $\left.\mathrm{MHz}, \mathrm{DMSO}-\mathrm{d}_{6}\right) \delta 1.42-1.46(\mathrm{~d}, J=7.1 \mathrm{~Hz}, 6 \mathrm{H}), 2.35(\mathrm{~s}, 3 \mathrm{H}), 4.87-4.94(\mathrm{hp}, J=7.1 \mathrm{~Hz}, 1 \mathrm{H}), 6.72-6.76$ (br s, 2H), 7.22-7.26 (d, $J=8.1 \mathrm{~Hz}, 1 \mathrm{H}$ ), 7.38.7.42 (overlapping $\mathrm{s}$ and $\mathrm{d}, 2 \mathrm{H}$ ), 7.46-7.52 (br s, 2H).

HRMS (ESI) calculated for $\mathrm{C}_{16} \mathrm{H}_{17} \mathrm{~N}_{7} \mathrm{O}[\mathrm{M}+\mathrm{H}]^{+} 324.1567$, found 324.1567 .

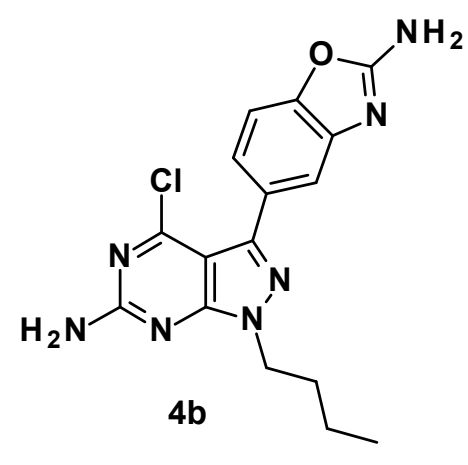

5-(6-Amino-1-butyl-4-chloro-1H-pyrazolo[3,4-d]pyrimidin-3-yl)benzo[d]oxazol-2-amine (4b)

4-Chloro-3-iodo-1H-pyrazolo[3,4-d]pyrimidin-6-amine (4.00 g, $4.06 \mathrm{mmol}, 1.00 \mathrm{eq}$.) was dissolved in DMF $(14.4 \mathrm{ml})$ and cesium carbonate $(1.32 \mathrm{~g}, 4.06 \mathrm{mmol}, 1.00 \mathrm{eq}$.$) was added followed by 1$ iodobutane $(0.55 \mathrm{ml}, 4.87 \mathrm{mmol}, 1.20$ eq.) at room temperature for $18 \mathrm{~h}$. Water was added and the reaction mixture was extracted into EtOAc. The suspension was filtered and the organic phase was separated, washed with water and dried over $\mathrm{MgSO}_{4}$ and concentrated to dryness. The residue was purified by flash chromatography (silica gel, heptane:EtOAc 8:2) to afford the alkylated intermediate (593 mg, 42\%) as a yellow soilid: LCMS ( $t_{R}=1.22$ min., purity= 99\%), $E S I+m / z 352(M+H)^{+}$.

In a microwave tube, was added 1-butyl-4-chloro-3-iodo- $1 H$-pyrazolo[3,4- $d$ ]pyrimidin-6-amine (543 $\mathrm{mg}, 1.54 \mathrm{mmol}, 1.00$ eq.), 5-(4,4,5,5-tetramethyl-1,3,2-dioxaborolan-2-yl)benzo[d]oxazol-2-amine amine (603 mg, $2.32 \mathrm{mmol}, 1.50$ eq.) to a mixture of 1,4-dioxane $(5.28 \mathrm{ml}$ ) and a $2.0 \mathrm{M}$ aqueous solution of potassium carbonate $(2.32 \mathrm{ml}, 4.63 \mathrm{mmol}, 3.00$ eq.). The reaction mixture was degassed and purged with argon. 1,1'-Bis(diphenylphosphino)ferrocene-palladium(II) dichloride, dichloromethane (126 mg, $0.15 \mathrm{mmol}, 0.10$ eq.) was added rapidly and the reaction mixture was heated at $100{ }^{\circ} \mathrm{C}$ for 60 minutes, cooled to room temperature, concentrated and purified directly by mass-triggered preparative LCMS (acidic conditions) to afford the title compound (4b, $171 \mathrm{mg}, 31 \%$ ): LCMS $\left(t_{\mathrm{R}}=1.08\right.$ min., purity= 99\%), ESI+ m/z $358(\mathrm{M}+\mathrm{H})^{+} ;{ }^{1} \mathrm{H}$ NMR (DMSO- $\left.d_{6}\right) \delta 0.82(\mathrm{t}, J=7.3 \mathrm{~Hz}, 2 \mathrm{H})$, $1.83(\mathrm{~h}, \mathrm{~J}=7.3 \mathrm{~Hz}, 2 \mathrm{H}$ ), $4.21(\mathrm{t}, J=7.3 \mathrm{~Hz}, 1 \mathrm{H}$ ), $7.20-7.27$ (overlapping signals br $\mathrm{s}$ and d, $3 \mathrm{H}$ ), 7.35 (d, $J=8.2 \mathrm{~Hz}, 1 \mathrm{H}$ ), $7.46-7.49$ (overlapping signals br s and s, 3H).

HRMS (ESI) calculated for $\mathrm{C}_{16} \mathrm{H}_{14} \mathrm{ClN} 7 \mathrm{O}[\mathrm{M}+\mathrm{H}]^{+} 344.1021$, found 344.1019 . 


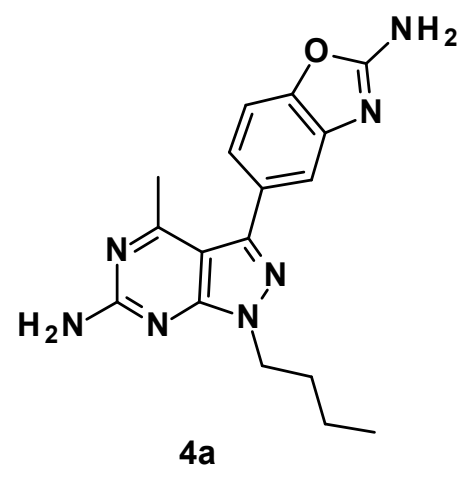

\section{5-(6-Amino-1-butyl-4-methyl-1H-pyrazolo[3,4-d]pyrimidin-3-yl)benzo[d]oxazol-2-amine (4a)}

5-(6-amino-1-butyl-4-chloro-1H-pyrazolo[3,4-d]pyrimidin-3-yl)benzo[d]oxazol-2-amine (80.0 mg, 0.22 mmol, 1.00 eq.) was dissolved in THF $(500 \mu \mathrm{l})$ and bis(tri-t-butylphosphine)palladium(0) $(13.0 \mathrm{mg}$, $0.01 \mathrm{mmol}, 0.05$ eq.) was added at $0{ }^{\circ} \mathrm{C}$. The reaction mixture was degassed and purged with argon and a solution of dimethylzinc in THF $(0.37 \mathrm{ml}, 0.45 \mathrm{mmol}, 2.00$ eq. $)$ was added keeping the temperature at $0{ }^{\circ} \mathrm{C}$. The reaction mixture was stirred at room temperature overnight, quenched with a saturated aqueous solution of ammonium chloride and extracted with EtOAc. The organic phase was washed with brine, dried over $\mathrm{MgSO}_{4}$ and concentrated to dryness. The residue was purified by mass-triggered preparative HPLC (acidic method) to afford the title compound (4a, 51.1 $\mathrm{mg}, 70 \%)$ as an orange solid. LCMS ( $t_{\mathrm{R}}=3.19 \mathrm{~min}$., purity=97\%, [C1-ACN-Full Range $7.5 \mathrm{~min}$, positive ionization, UV $254 \mathrm{~nm}$ ]), $\mathrm{ESI}+\mathrm{m} / \mathrm{z} 338(\mathrm{M}+\mathrm{H})^{+} ; \mathrm{Rf}=0.15$ (Hex/EtOAc:1/1) [SiO2 ; UV, KMnO4]; ${ }^{1 \mathrm{H}} \mathrm{NMR}$ $\left(400 \mathrm{MHz}, \mathrm{DMSO}-d_{6}\right) \delta 0.90(\mathrm{t}, \mathrm{J}=7.4 \mathrm{~Hz}, 3 \mathrm{H}), 1.36-1.19(\mathrm{~m}, 2 \mathrm{H}), 1.71-1.85(\mathrm{~m}, 2 \mathrm{H}), 2.35(\mathrm{~s}, 3 \mathrm{H})$, $4.18(\mathrm{t}, \mathrm{J}=7.0 \mathrm{~Hz}, 2 \mathrm{H}), 6.78(\mathrm{~s}, 2 \mathrm{H}), 7.16-7.27(\mathrm{~m}, 1 \mathrm{H}), 7.34-7.44(\mathrm{~m}, 2 \mathrm{H}), 7.49(\mathrm{~s}, 2 \mathrm{H})$.

HRMS (ESI) calculated for $\mathrm{C}_{16} \mathrm{H}_{19} \mathrm{~N}_{7} \mathrm{O}[\mathrm{M}+\mathrm{H}]^{+} 337.1651$, found 337.1650.<smiles>CCc1nc(N)nc2c1c(-c1ccc3oc(N)nc3c1)nn2C(C)C</smiles>

5-(6-Amino-4-ethyl-1-isopropyl-1H-pyrazolo[3,4- $d]$ pyrimidin-3-yl)benzo[d]oxazol-2-amine (3b)

5-(6-amino-4-chloro-1-isopropyl-1H-pyrazolo[3,4- $d$ ]pyrimidin-3-yl)benzo[d]oxazol-2-amine $3 e$ (75.0 $\mathrm{mg}, 0.22 \mathrm{mmol}, 1.00$ eq.) was dissolved in THF $(2.00 \mathrm{ml})$. The reaction mixture was degassed and purged with argon then cooled to $0{ }^{\circ} \mathrm{C}$. Bis(tri-t-butylphosphine)palladium(0) $(22.3 \mathrm{mg}, 0.04 \mathrm{mmol}$, 0.20 eq.) was added followed by diethylzinc $(0.87 \mathrm{ml}, 1.00 \mathrm{M}, 0.87 \mathrm{mmol} ;, 4.00$ eq.). The reaction mixture was stirred at room temperature for $1 \mathrm{~h}$, quenched with a saturated aqeous solution of $\mathrm{NH}_{4} \mathrm{Cl}$, extracted into EtOAc. The organic phase was washed with brine, dried over $\mathrm{MgSO}_{4}$ and concentrated to dryness. The residue was purified by mass-triggered preparative HPLC to afford the title compound (3b, $15.1 \mathrm{mg}, 21 \%)$ as a pale yellow solid: LCMS ( $t_{\mathrm{R}}=0.93 \mathrm{~min}$., purity $\left.=99 \%\right), \mathrm{ESI}+\mathrm{m} / \mathrm{z}$ $338(\mathrm{M}+\mathrm{H})^{+} ;{ }^{1} \mathrm{H}$ NMR $\left(400 \mathrm{MHz}, \mathrm{DMSO}-d_{6}\right) \delta 1.02(\mathrm{t}, \mathrm{J}=7.5 \mathrm{~Hz}, 3 \mathrm{H}), 1.45(\mathrm{~d}, \mathrm{~J}=6.7 \mathrm{~Hz}, 6 \mathrm{H}), 2.63-2.71$ $(\mathrm{m}, 2 \mathrm{H}), 4.90(\mathrm{~h}, \mathrm{~J}=6.7 \mathrm{~Hz}, 1 \mathrm{H}), 6.74(\mathrm{~s}, 2 \mathrm{H}), 7.17(\mathrm{dd}, \mathrm{J}=8.2,1.7 \mathrm{~Hz}, 1 \mathrm{H}), 7.36(\mathrm{~d}, \mathrm{~J}=1.6 \mathrm{~Hz}, 1 \mathrm{H}), 7.41$ $(\mathrm{d}, \mathrm{J}=8.2 \mathrm{~Hz}, 1 \mathrm{H}), 7.49(\mathrm{~s}, 2 \mathrm{H})$. 
HRMS (ESI) calculated for $\mathrm{C}_{17} \mathrm{H}_{19} \mathrm{~N}_{7} \mathrm{O}[\mathrm{M}+\mathrm{H}]^{+} 338.1724$, found 338.1721 .

Preparation of (6-Amino-3-(2-aminobenzo[d]oxazol-5-yl)-1-isopropyl-1H-pyrazolo[3,4-d]pyrimidin4-yl)methanol (3c)

The title compound $\mathbf{3 c}$ was prepared using the following sequence:

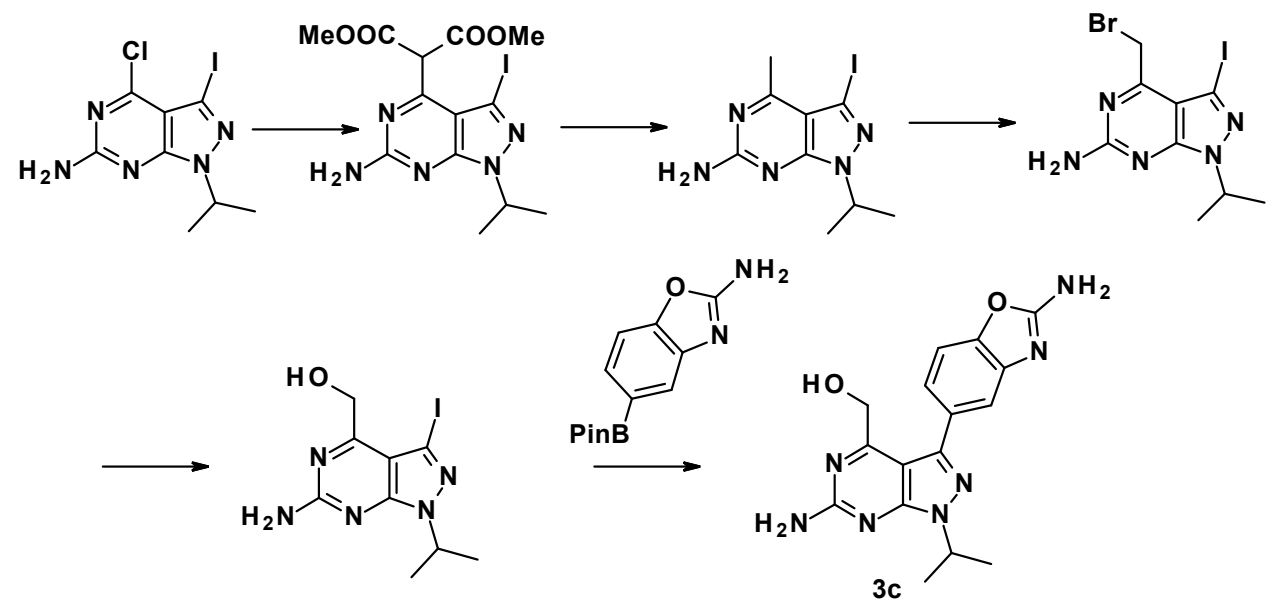

\section{Dimethyl 2-(6-amino-3-iodo-1-isopropyl-1H-pyrazolo[3,4-d]pyrimidin-4-yl)malonate}

To a stirred suspension of 4-chloro-3-iodo-1-isopropyl-1H-pyrazolo[3,4- $d$ ]pyrimidin-6-ylamine (2.00 g, $5.93 \mathrm{mmol}, 1.00$ eq.) and cesium carbonate $(4.63 \mathrm{~g}, 14.2 \mathrm{mmol}, 2.40$ eq.) in DMSO (13.2 ml) at room temperature, was added dimethyl malonate $(1.88 \mathrm{~g}, 14.2 \mathrm{mmol}, 2.40 \mathrm{eq}$.$) . The resulting suspension$ was heated at $100{ }^{\circ} \mathrm{C}$ for $2 \mathrm{~h} 15 \mathrm{~min}$ to afford a yellow suspension. The reaction mixture was cooled to room temperature and water was added. The reaction mixture was extracted into EtOAc and the organic phase was recuperated, washed with water, dried over $\mathrm{MgSO}_{4}$ and concentrated to dryness to afford the title compound $(2.60 \mathrm{~g}, 95 \%)$ as a yellow solid that was used without further purification: LCMS $\left(t_{\mathrm{R}}=1.08 \mathrm{~min}\right.$., purity= 94\%), ESI+ m/z $434(\mathrm{M}+\mathrm{H})^{+} ;{ }^{1} \mathrm{H}$ NMR $\left(400 \mathrm{MHz}, \mathrm{DMSO}-d_{6}\right) \delta$ $1.43(\mathrm{~d}, J=6.6 \mathrm{~Hz}, 6 \mathrm{H}), 3.78(\mathrm{~s}, 6 \mathrm{H}), 4.78-4.86$ (hept, $J=6.6 \mathrm{~Hz}, 1 \mathrm{H}), 5.62(\mathrm{~s}, 1 \mathrm{H}), 7.13(\mathrm{br} \mathrm{s}, 2 \mathrm{H})$.

\section{3-lodo-1-isopropyl-4-methyl-1H-pyrazolo[3,4-d]pyrimidin-6-amine}

Dimethyl 2-(6-amino-3-iodo-1-isopropyl-1H-pyrazolo[3,4-d]pyrimidin-4-yl)malonate $(2.40 \mathrm{~g} ; 5.54$ mmol; 1.00 eq.) was suspended in $6 \mathrm{~N} \mathrm{HCl}$ (aq) $(52 \mathrm{ml})$ and heated at $50{ }^{\circ} \mathrm{C}$ for 4 hours to afford a yellow solution. The reaction mixture was cooled to $0{ }^{\circ} \mathrm{C}$ and $8 \mathrm{~N} \mathrm{NaOH}$ was added to neutral $\mathrm{pH}$ and the reaction mixture was extracted into EtOAc. The organic phases was dried over $\mathrm{MgSO}_{4}$ and concentrated to dryness to afford the title compound $(1.60 \mathrm{~g}, 91 \%)$ as an orange solid: LCMS $\left(t_{R}=0.97\right.$ min., purity= 95\%), ESI+ m/z $318(\mathrm{M}+\mathrm{H})^{+} ;{ }^{1} \mathrm{H}$ NMR $\left(400 \mathrm{MHz}, \mathrm{DMSO}-d_{6}\right) \delta 1.42(\mathrm{~d}, J=6.7 \mathrm{~Hz}, 6 \mathrm{H}), 2.64$ $(\mathrm{s}, 3 \mathrm{H}), 4.74-4.84$ (hept, $J=6.7 \mathrm{~Hz}, 1 \mathrm{H}), 6.91(\mathrm{~s}, 2 \mathrm{H})$.

\section{(6-Amino-3-iodo-1-isopropyl-1H-pyrazolo[3,4-d]pyrimidin-4-yl)methanol}

To a stirred solution of 3-iodo-1-isopropyl-4-methyl-1H-pyrazolo[3,4-d]pyrimidin-6-amine (730 mg, $2.30 \mathrm{mmol}, 1.00$ eq.) in DCM (7.30 ml), were added $\mathrm{N}$-bromosuccinimide $(409 \mathrm{mg}, 2.30 \mathrm{mmol}, 1.00$ eq.) and benzoyl peroxide $(27.9 \mathrm{mg}, 0.12 \mathrm{mmol}, 0.05 \mathrm{eq})$ and the reaction mixture was heated at 70 
${ }^{\circ} \mathrm{C}$ for $10 \mathrm{~h}$. The reaction mixture was evaporated to dryness, dissolved in DMF and purified directly by mass-triggered preparative LCMS to afford the title compound (480 $\mathrm{mg}, 53 \%$ ) as an orange solid : LCMS $\left(t_{R}=1.19\right.$ min., purity= 97\%), ESI+ m/z $396(\mathrm{M}+\mathrm{H})^{+}$. 4-(Bromomethyl)-3-iodo-1-isopropyl- $1 \mathrm{H}$ pyrazolo[3,4- $d$ ] pyrimidin-6-amine was directly engaged in the next step without further purification.

3-lodo-1-isopropyl-4-methyl-1H-pyrazolo[3,4- $d$ ] pyrimidin-6-amine $(480 \mathrm{mg}, 1.21 \mathrm{mmol}, 1.00$ eq.) was dissolved in DMSO $(4.8 \mathrm{ml})$ and $\mathrm{NaHCO}_{3}(305 \mathrm{mg}, 3.64 \mathrm{mmol}, 3.00$ eq.) was added and the reaction mixture was stirred at $50{ }^{\circ} \mathrm{C}$ for $16 \mathrm{~h}$. The reaction mixture was purified directly by masstriggered preparative LCMS to afford the title compound $(60.0 \mathrm{mg}, 15 \%)$ as a beige solid: LCMS $\left(t_{\mathrm{R}}=0.96\right.$ min., purity= 97\%), ESI+ m/z $334(\mathrm{M}+\mathrm{H})^{+} ;{ }^{1} \mathrm{H}$ NMR (DMSO- $\left.d_{6}\right) \delta 1.40(\mathrm{~d}, J=6.7 \mathrm{~Hz}, 6 \mathrm{H}), 4.83$ $(\mathrm{dd}, J=6.1,4.2 \mathrm{~Hz}, 3 \mathrm{H}), 5.14(\mathrm{t}, J=5.6 \mathrm{~Hz}, 1 \mathrm{H}), 7.03(\mathrm{~s}, 2 \mathrm{H})$.<smiles>CC(C)n1nc(-c2ccc3oc(N)nc3c2)c2c(CO)nc(N)nc21</smiles>

(6-Amino-3-(2-aminobenzo[d]oxazol-5-yl)-1-isopropyl-1H-pyrazolo[3,4-d]pyrimidin-4-yl)methanol (3c)

In a microwave tube was added (6-amino-3-iodo-1-isopropyl-1H-pyrazolo[3,4- $d$ ]pyrimidin-4yl)methanol $(60.0 \mathrm{mg}, \quad 0.18 \mathrm{mmol}, 1.00$ eq.), 5-(4,4,5,5-tetramethyl-1,3,2-dioxaborolan-2yl)benzo[d]oxazol-2-amine (70.3 $\mathrm{mg}, 0.27 \mathrm{mmol}, 1.50$ eq.), a $2.0 \mathrm{M}$ aqueous solution of potassium carbonate $(0.27 \mathrm{ml}, 0.54 \mathrm{mmol}, 3.00$ eq.) and 1,4-dioxane $(0.48 \mathrm{ml})$. The reaction mixture was degassed and purged with argon before 1,1'-bis(diphenylphosphino)ferrocenepalladium(II) dichloride.dichloromethane $(14.7 \mathrm{mg}, 0.02 \mathrm{mmol}, 0.10$ eq.) was added. The reaction mixture was heated at $100{ }^{\circ} \mathrm{C}$ for $30 \mathrm{~min}$. The reaction mixture was cooled to room temperature wans purified directly by mass-triggered preparativeLCMS (acidic conditions) to afford the title compound (3c, 11.1 $\mathrm{mg}, 18.2 \%)$ : LCMS ( $t_{\mathrm{R}}=0.87$ min., purity= 99\%), ESI+ m/z $340(\mathrm{M}+\mathrm{H}){ }^{+} ;{ }^{1} \mathrm{H}$ NMR (DMSO- $\left.d_{6}\right) \delta 1.47(\mathrm{~d}, J=$ $6.7 \mathrm{~Hz}, 6 \mathrm{H}), 4.49(\mathrm{~d}, J=5.5 \mathrm{~Hz}, 2 \mathrm{H}), 4.93(\mathrm{~h}, J=6.6 \mathrm{~Hz}, 1 \mathrm{H}), 5.01(\mathrm{t}, J=5.5 \mathrm{~Hz}, 1 \mathrm{H}), 6.88(\mathrm{~s}, 2 \mathrm{H}), 7.27$ (dd, $J=8.2,1.7 \mathrm{~Hz}, 1 \mathrm{H}), 7.40(\mathrm{~d}, J=8.1 \mathrm{~Hz}, 1 \mathrm{H}), 7.42-7.54(\mathrm{~m}, 3 \mathrm{H})$.

HRMS (ESI) calculated for $\mathrm{C}_{16} \mathrm{H}_{17} \mathrm{~N}_{7} \mathrm{O}_{2}[\mathrm{M}+\mathrm{H}]^{+} 340.1516$, found 340.1511

\section{Preparation}

of:5-(6-Amino-1-isopropyl-4-methoxy-1H-pyrazolo[3,4-d]pyrimidin-3-

\section{yl)benzo[d]oxazol-2-amine (3d)}

The title compound $\mathbf{3} \mathbf{d}$ was prepared using the following sequence:<smiles>CC(C)n1nc(I)c2c(Cl)nc(N)nc21</smiles><smiles>COc1nc(N)nc2c1c(I)nn2C(C)C</smiles><smiles>CPc1ccc2oc(N)nc2c1</smiles><smiles>COc1nc(N)nc2c1c(-c1ccc3oc(N)nc3c1)nn2C(C)C</smiles> 


\section{3-Iodo-1-isopropyl-4-methoxy-1H-pyrazolo[3,4-d]pyrimidin-6-amine}

To a stirred solution of 4-chloro-3-iodo-1-isopropyl-1H-pyrazolo[3,4-d]pyrimidin-6-amine (300 mg, $0.89 \mathrm{mmol}, 1.00$ eq.) in $\mathrm{MeOH}(2.0 \mathrm{ml})$ was added $30 \%$ solution of sodium methoxide in $\mathrm{MeOH}(0.49$ $\mathrm{ml}, 2.67 \mathrm{mmol}, 3.00$ eq.). The reaction mixture was stirred at room temperature for 30 minutes, quenched with a saturated solution of ammonium chloride and extracted into EtOAc. The organic phases were washed with brine, dried over $\mathrm{MgSO}_{4}$ and concentrated to dryness to afford the title compound ( $280 \mathrm{mg}, 95 \%)$ as an orange solid: $\mathrm{LCMS}\left(t_{\mathrm{R}}=1.18 \mathrm{~min}\right.$., purity= 99\%), ESI+ $\mathrm{m} / \mathrm{z} 334(\mathrm{M}+\mathrm{H})^{+}$; ${ }^{1} \mathrm{H} \mathrm{NMR}\left(\mathrm{DMSO}-d_{6}\right) \delta 1.37(\mathrm{~d}, J=6.6 \mathrm{~Hz}, 6 \mathrm{H}), 3.97(\mathrm{~s}, 3 \mathrm{H}), 4.76(\mathrm{~h}, J=6.6 \mathrm{~Hz}, 1 \mathrm{H}), 6.88(\mathrm{~s}, 2 \mathrm{H})$

5-(6-Amino-1-isopropyl-4-methoxy-1H-pyrazolo[3,4-d]pyrimidin-3-yl)benzo[d]oxazol-2-amine (3d)<smiles>COc1nc(N)nc2c1c(-c1ccc3oc(N)nc3c1)nn2C(C)C</smiles>

In a microwave tube, 3-lodo-1-isopropyl-4-methoxy-1H-pyrazolo[3,4-d]pyrimidin-6-amine $(98.0 \mathrm{mg}$, $0.29 \mathrm{mmol}, 1.00$ eq.) and a $2.0 \mathrm{M}$ aqueous solution of potassium carbonate $(0.44 \mathrm{ml}, 0.88 \mathrm{mmol}, 3.00$ eq.) in 1,4-dioxane (1.03 ml) were degassed and purged with argon. 1,1'Bis(diphenylphosphino)ferrocenepalladium(II) dichloride.dichloromethane $(24.0 \mathrm{mg}, 0.03 \mathrm{mmol}, 0.10$ eq.) was added followed by 5-(4,4,5,5-tetramethyl-1,3,2-dioxaborolan-2-yl)benzo[d]oxazol-2-amine (115 mg, $0.44 \mathrm{mmol}, 1.50$ eq.) and the reaction mixture was heated at $100{ }^{\circ} \mathrm{C}$ for $30 \mathrm{~min}$. The reaction mixture was cooled to room temperature. EtOAc was added and the reaction mixture filtered and the filtrate was concentrated and purified by mass-triggered preparative LCMS (basic conditions) to afford the title compound ( $3 \mathrm{~d}, 34 \mathrm{mg}, 34 \%)$ as a pale yellow solid: $\mathrm{LCMS}\left(t_{\mathrm{R}}=0.90 \mathrm{~min}\right.$., purity= 97\%), ESI+ m/z $340(\mathrm{M}+\mathrm{H})^{+} ;{ }^{1} \mathrm{H}$ NMR (DMSO- $\left.d_{6}\right) \delta 1.46(\mathrm{~d}, J=6.6 \mathrm{~Hz}, 6 \mathrm{H}), 3.99(\mathrm{~s}, 3 \mathrm{H}), 4.88(\mathrm{~h}$, $J=6.7 \mathrm{~Hz}, 1 \mathrm{H}), 6.76(\mathrm{~s}, 2 \mathrm{H}), 7.37(\mathrm{~d}, J=8.3 \mathrm{~Hz}, 1 \mathrm{H}), 7.42(\mathrm{~s}, 2 \mathrm{H}), 7.59(\mathrm{dd}, J=8.3,1.7 \mathrm{~Hz}, 1 \mathrm{H}), 7.75(\mathrm{~d}, J$ $=1.6 \mathrm{~Hz}, 1 \mathrm{H})$.

HRMS (ESI) calculated for $\mathrm{C}_{16} \mathrm{H}_{17} \mathrm{~N}_{7} \mathrm{O}_{4}[\mathrm{M}+\mathrm{H}]^{+} 340.1516$, found 340.1515

Preparation of 5-(6-Amino-4-fluoro-1-isopropyl-1H-pyrazolo[3,4-d]pyrimidin-3-yl)benzo[d]oxazol2-amine (3f)

The title compound $\mathbf{3 f}$ was prepared using the following sequence:<smiles>CC(C)n1nc(I)c2c(Cl)nc(N)nc21</smiles><smiles>CC(C)n1nc(I)c2c(F)nc(N)nc21</smiles><smiles>CC([Si])n1nc(-c2ccc3oc(N)nc3c2)c2c(F)nc(N)nc21</smiles>

5-(6-Amino-4-fluoro-1-isopropyl-1H-pyrazolo[3,4-d]pyrimidin-3-yl)benzo[d]oxazol-2-amine (3f) 
To a stirred solution of 4-chloro-3-iodo-1-isopropyl-1H-pyrazolo[3,4- $d$ ]pyrimidin-6-amine (300 mg, $0.89 \mathrm{mmol}, 1.00$ eq.) in THF $(3.00 \mathrm{ml})$ was added triethylamine $(0.15 \mathrm{ml}, 1.07 \mathrm{mmol}, 1.20$ eq.) followed by a $1.0 \mathrm{M}$ solution of tetrabutylammonium fluoride $(0.89 \mathrm{ml}, 0.89 \mathrm{mmol}, 1.00 \mathrm{eq}$.). The reaction mixture was heated at $80^{\circ} \mathrm{C}$ for 11 , cooled to room temperature and diluted with EtOAc. The reaction mixture was washed with brine and the organic phase separated, dried over $\mathrm{MgSO}_{4}$ and concentrated to dryness. The residue was purified by mass-triggered preparative LCMS to afford the title compound (150 mg, 53\%) as a yellow solid: LCMS ( $t_{R}=1.09$ min., purity= 99\%), ESI+ m/z 322 $\left.(\mathrm{M}+\mathrm{H})^{+} ;\right)^{+} ;{ }^{1} \mathrm{H}$ NMR $\left(\mathrm{DMSO}_{-} \mathrm{d}_{6}\right) \delta 1.42(\mathrm{~d}, J=6.7 \mathrm{~Hz}, 6 \mathrm{H}), 4.81(\mathrm{~h}, J=6.7 \mathrm{~Hz}, 1 \mathrm{H}), 7.38(\mathrm{br} \mathrm{s}, 2 \mathrm{H})$.

In a microwave tube, 4-fluoro-3-iodo-1-isopropyl-1H-pyrazolo[3,4- $d$ ]pyrimidin-6-amine $(20.0 \mathrm{mg}$, $0.06 \mathrm{mmol}, 1.00$ eq.) was added to a mixture of a $2.0 \mathrm{M}$ aqueous solution of potassium carbonate (0.09 ml, $0.19 \mathrm{mmol}, 3.00$ eq.) and 5-(4,4,5,5-tetramethyl-1,3,2-dioxaborolan-2-yl)benzo[d]oxazol-2amine amine ( $24.3 \mathrm{mg}, 0.09 \mathrm{mmol}, 1.50$ eq.) in 1,4-dioxane $(0.24 \mathrm{ml})$. The reaction mixture was degassed and purged with argon. 1,1'-Bis(diphenylphosphino)ferrocene-palladium(II) dichloride, dichloromethane $(5.1 \mathrm{mg}, 0.01 \mathrm{mmol}, 0.10$ eq.) was added and the reaction mixture was heated at $100{ }^{\circ} \mathrm{C}$ for 30 minutes, cooled to room temperature and $\mathrm{MeOH}$ was added. The reaction mixture was filtered, concentrated and purified directly by mass-triggered preparative LCMS (basic conditions) to afford the title compound $3 \mathrm{f}(6 \mathrm{mg}, 31 \%) . \delta 1.49(\mathrm{~d}, J=6.6 \mathrm{~Hz}, 6 \mathrm{H}), 4.92(\mathrm{~h}, J=6.9 \mathrm{~Hz}, 1 \mathrm{H}), 7.25(\mathrm{~s}$, $2 \mathrm{H}), 7.43(\mathrm{~d}, J=8.4 \mathrm{~Hz}, 1 \mathrm{H}), 7.51(\mathrm{~d}, J=4.7 \mathrm{~Hz}, 3 \mathrm{H}), 7.65(\mathrm{~s}, 1 \mathrm{H})$.

HRMS (ESI) calculated for $\mathrm{C}_{16} \mathrm{H}_{26} \mathrm{~N}_{3} \mathrm{O}_{4}[\mathrm{M}+\mathrm{H}]^{+} 328.1317$, found 328.1310 .

Preparation of 5-(6-Amino-4-bromo-1-isopropyl-1H-pyrazolo[3,4-d]pyrimidin-3-yl)benzo[d]oxazol2-amine (3g)

The title compound $\mathbf{3 g}$ was prepared starting directly from previously described $\mathbf{3 e}$.<smiles>CC(C)n1nc(-c2ccc3oc(N)nc3c2)c2c(Br)nc(N)nc21</smiles>

5-(6-Amino-4-chloro-1-isopropyl-1H-pyrazolo[3,4-d]pyrimidin-3-yl)benzo[d]oxazol-2-amine (200 mg, $0.29 \mathrm{mmol}, 1.00$ eq.) was dissolved in DCM $(1 \mathrm{ml})$. A $1.0 \mathrm{M}$ solution of $\mathrm{BBr}_{3}$ in DCM $(0.58 \mathrm{ml}, 0.58$ $\mathrm{mmol}, 2.00$ eq.) was added and the reaction mixture was stirred at room temperature for 45 minutes under argon. The reaction mixture was quenched with water and extracted into DCM. The organic phases were combined, dried over $\mathrm{MgSO}_{4}$ and concentrated to dryness. The residue was purified by mass-triggered preparative LCMS (acidic conditions) to afford the title compound (5.8 $\mathrm{mg}, 5 \%$ ) as an orange solid: LCMS $\left(t_{\mathrm{R}}=3.71 \mathrm{~min}\right.$., purity=91.4\%), ESI+ $\mathrm{m} / \mathrm{z} 388(\mathrm{M}+\mathrm{H})^{+} ;{ }^{1} \mathrm{H}$ NMR (DMSO- $\left.d_{6}\right) \delta 1.46(\mathrm{~d}$, $J=6.7 \mathrm{~Hz}, 6 \mathrm{H}), 4.90(\mathrm{~h}, J=6.7 \mathrm{~Hz}, 1 \mathrm{H}), 7.25(\mathrm{td}, J=8.2,2.2 \mathrm{~Hz}, 3 \mathrm{H}), 7.40(\mathrm{~d}, J=8.3 \mathrm{~Hz}, 1 \mathrm{H}), 7.43(\mathrm{~d}, J=$ $1.7 \mathrm{~Hz}, 1 \mathrm{H}), 7.48(\mathrm{~s}, 2 \mathrm{H})$.

HRMS (ESI) calculated for $\mathrm{C}_{15} \mathrm{H}_{14} \mathrm{BrN}_{7} \mathrm{O}[\mathrm{M}+\mathrm{H}]^{+}$388.0516, found 388.1070.

Preparation of 5-(6-Amino-1-isopropyl-4-(trifluoromethyl)-1H-pyrazolo[3,4-d]pyrimidin-3yl)benzo[d]oxazol-2-amine (3h) 
The title compound $\mathbf{3 h}$ was prepared following the sequence below:
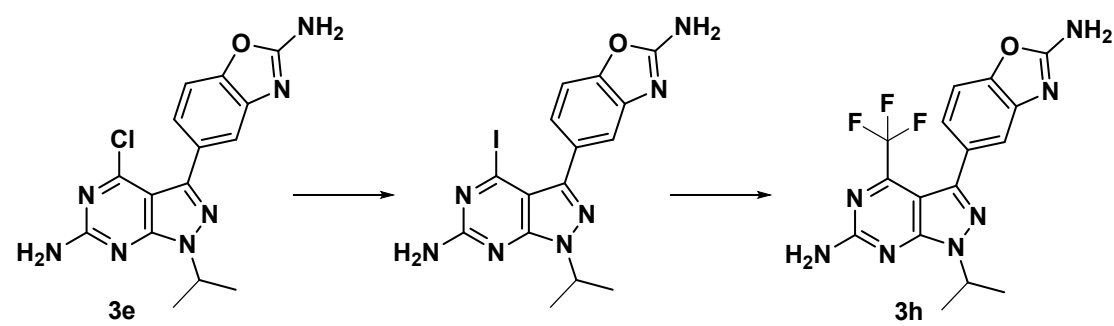

\section{5-(6-Amino -4-iodo-1-isopropyl-1H-pyrazolo[3,4-d]pyrimidin-3-yl)benzo[d]oxazol-2-amine}

To a stirred suspension of 5-(6-amino-4-chloro-1-isopropyl-1H-pyrazolo[3,4- $d$ ] pyrimidin-3yl)benzo[ $d$ ] oxazol-2-amine and sodium iodide $\left(1.74 \mathrm{~g}, 11.6 \mathrm{mmol}, 20 \mathrm{eq}\right.$.) at $0^{\circ} \mathrm{C}$, was added hydriodic acid $(2.00 \mathrm{ml}, 40 \% \mathrm{w} / \mathrm{w}, 8.73 \mathrm{mmol}, 15$ eq.) and the suspension was stirred at room temperature for $4 \mathrm{~h}$. The reaction mixture was diluted with DCM and pour onto a saturated aqueous solution of $\mathrm{NaHCO}_{3}$. The aqueous phase was extracted with DCM. The organic phases were combined, washed with a $1 \mathrm{M}$ solution of sodium thiosulfate, water, dried over $\mathrm{MgSO}_{4}$ and concentrated to dryness to afford the title compound ( $150 \mathrm{mg}, 59 \%)$ as a beige solid: $\mathrm{LCMS}\left(t_{\mathrm{R}}=2,70 \mathrm{~min}\right.$., purity $\left.=97 \%\right), \mathrm{ESI}+\mathrm{m} / \mathrm{z}$ $436(\mathrm{M}+\mathrm{H})^{+} ;{ }^{1} \mathrm{H}$ NMR $\left(\right.$ DMSO$\left.d_{6}\right) \delta 1.46(\mathrm{~d}, J=6.7 \mathrm{~Hz}, 6 \mathrm{H}), 4.90(\mathrm{~h}, J=6.7 \mathrm{~Hz}, 1 \mathrm{H}), 7.18(\mathrm{~m}, 1 \mathrm{H}), 7.28$ $(\mathrm{m}, 2 \mathrm{H}), 7.40(\mathrm{~m}, 2 \mathrm{H}), 7.47$ (br s, 2H).<smiles>CC(c1ccccc1)n1nc(-c2ccc3oc(N)nc3c2)c2c(C(F)(F)F)nc(N)nc21</smiles>

\section{5-(6-Amino-1-isopropyl-4-(trifluoromethyl)-1H-pyrazolo[3,4-d]pyrimidin-3-yl)benzo[d]oxazol-2-} amine (3h)

To a stirred solution of 5-(6-amino-4-iodo-1-isopropyl-1H-pyrazolo[3,4- $d$ ]pyrimidin-3yl)benzo[d]oxazol-2-amine (70.0 mg, $0.11 \mathrm{mmol}, 1.00 \mathrm{eq}$.) in DMF $(1.37 \mathrm{ml})$ under argon, was added (1,10-phenanthroline)(trifluoromethyl)copper(I) $(59.9 \mathrm{mg}, 0.19 \mathrm{mmol}, 1.70$ eq.) and the reaction mixture was stirred at room temperature for $1 \mathrm{~h}$. The reaction mixture was filtered through a pad of Celite and concentrated to dryness. The residue was purified by mass-triggered preparative LCMS (acidic conditions), concentrated to dryness and the solid triturated in a methanolic ammonia solution. The solid was collected by filtration and dried to a constant weight to afford the title compound ( $3 \mathrm{~h}, 10.3 \mathrm{mg}, 24 \%)$ as a beige solid: LCMS ( $t_{\mathrm{R}}=0.99 \mathrm{~min}$., purity= 97\%), ESI+ $\mathrm{m} / \mathrm{z} 378$ $(\mathrm{M}+\mathrm{H})^{+} ;{ }^{1} \mathrm{H}$ NMR (DMSO- $\left.d_{6}\right) \delta 1.48(\mathrm{~d}, J=6.7 \mathrm{~Hz}, 6 \mathrm{H}), 4.98(\mathrm{~h}, J=6.7 \mathrm{~Hz}, 1 \mathrm{H}), 7.07(\mathrm{dd}, J=8.1,1.6 \mathrm{~Hz}$, $1 \mathrm{H}), 7.26(\mathrm{~d}, J=1.6 \mathrm{~Hz}, 1 \mathrm{H}), 7.39(\mathrm{~d}, J=8.1 \mathrm{~Hz}, 1 \mathrm{H}), 7.47(\mathrm{~d}, J=12.3 \mathrm{~Hz}, 4 \mathrm{H})$.

HRMS (ESI) calculated for $\mathrm{C}_{16} \mathrm{H}_{14} \mathrm{~F}_{3} \mathrm{~N}_{7} \mathrm{O}[\mathrm{M}+\mathrm{H}]^{+} 378.1285$, found 378.1281 .

Preparation of: 6-Amino-3-(2-aminobenzo[d]oxazol-5-yl)-1-isopropyl-1H-pyrazolo[3,4d] pyrimidine-4-carbonitrile (3i) 
The title compound $\mathbf{3 i}$ was prepared following the sequence below:<smiles>CC(C)n1nc(I)c2c(Cl)nc(N)nc21</smiles><smiles>CC(C)n1nc(I)c2c(C#N)nc(N)nc21</smiles><smiles>CC(C)n1nc(-c2ccc3oc(N)nc3c2)c2c(C#N)nc(N)nc21</smiles><smiles>CC(C)n1nc(-c2ccc3oc(N)nc3c2)c2c(C#N)nc(N)nc21</smiles>

\section{6-Amino-3-(2-aminobenzo[d]oxazol-5-yl)-1-isopropyl-1H-pyrazolo[3,4- $d$ ]pyrimidine-4-carbonitrile} (3i)

To a stirred solution of 4-chloro-3-iodo-1-isopropyl-1H-pyrazolo[3,4-d]pyrimidin-6-amine (500 mg, $1.48 \mathrm{mmol}, 1.00$ eq.) and 18-CROWN-6 (235 mg, $0.89 \mathrm{mmol}, 0.60$ eq.) in MeCN (5.0 ml), was added potassium cyanide $(96.5 \mathrm{mg}, 1.48 \mathrm{mmol}, 1.00$ eq.) and the reaction mixture was stirred under reflux for $1 \mathrm{~h} 40 \mathrm{~min}$. The reaction mixture was diluted with brine ( $\mathrm{pH}$ was basique), and the the aqueous phase was extracted with EtOAc. The organic phases were combinedm washed with brine, dried over $\mathrm{MgSO}_{4}$ and concentrated to dryness to afford the title compound (474 $\mathrm{mg}, 85 \%$ ) as a yellow soild that was used without further purification: LCMS $\left(t_{R}=1.11\right.$ min., purity= $\left.94 \%\right), E S I+m / z 329(M+H)^{+}$.

In a microwave tube, 6-amino-3-iodo-1-isopropyl-1H-pyrazolo[3,4- $d$ ] pyrimidine-4-carbonitrile (40.0 mg, $0.12 \mathrm{mmol}, 1.00$ eq., 5-(4,4,5,5-tetramethyl-1,3,2-dioxaborolan-2-yl)benzo[d]oxazol-2amine $(47.6 \mathrm{mg}, 0.18 \mathrm{mmol}, 1.50$ eq.) was added to a mixture of a $2.0 \mathrm{M}$ aqueous solution of potassium carbonate $(0.18 \mathrm{ml}, 0.37 \mathrm{mmol}, 3.00$ eq.) and 5-(4,4,5,5-tetramethyl-1,3,2-dioxaborolan-2yl)benzo[d]oxazol-2-amine amine $(24.3 \mathrm{mg}, 0.09 \mathrm{mmol}, 1.50$ eq.) and in 1,4-dioxane $(0.42 \mathrm{ml})$. The reaction mixture was degassed and purged with argon. 1,1'-Bis(diphenylphosphino)ferrocenepalladium(II) dichloride, dichloromethane $(10 \mathrm{mg}, 0.01 \mathrm{mmol}, 0.10 \mathrm{eq}$.) was added and the reaction mixture was heated at $90{ }^{\circ} \mathrm{C}$ for $16 \mathrm{~h}$, cooled to room temperature filtered through a pad of Celite and concentrated to dryness. The residue was purified directly by mass-triggered preparative LCMS (acidic conditions) to afford the title compound $(3 \mathbf{i}, 5.0 \mathrm{mg}, 12 \%)$ as a yellow solid: LCMS $\left(t_{\mathrm{R}}=0.94 \mathrm{~min} .\right.$, purity= 98\%), ESI+ m/z $335(\mathrm{M}+\mathrm{H})^{+} ;{ }^{1} \mathrm{H}$ NMR (DMSO- $\left.d_{6}\right) \delta 1.49(\mathrm{~d}, J=6.7 \mathrm{~Hz}, 6 \mathrm{H}), 4.94$ $(\mathrm{h}, J=6.7 \mathrm{~Hz}, 1 \mathrm{H}), 7.41(\mathrm{dd}, J=8.3,1.7 \mathrm{~Hz}, 1 \mathrm{H}), 7.46(\mathrm{~d}, J=8.2 \mathrm{~Hz}, 3 \mathrm{H}), 7.53(\mathrm{~s}, 2 \mathrm{H}), 7.60(\mathrm{~d}, J=1.9 \mathrm{~Hz}$, $1 \mathrm{H})$.

HRMS (ESI) calculated for $\mathrm{C}_{16} \mathrm{H}_{14} \mathrm{~N}_{8} \mathrm{O}[\mathrm{M}+\mathrm{H}]^{+} 335.1363$, found 335.1360 .

Preparation of 3-(2-Aminobenzo[d]oxazol-5-yl)-1-isopropyl-1H-pyrazolo[3,4-d]pyrimidine-4,6diamine (3j) 
The title compound $\mathbf{3} \mathbf{j}$ was prepared following the sequence below:<smiles>CC(C)n1nc(I)c2c(Cl)nc(N)nc21</smiles><smiles>CC(C)n1nc(I)c2c(N)nc(N)nc21</smiles><smiles>CC(C)n1nc(-c2ccc3oc(N)nc3c2)c2c(N)nc(N)nc21</smiles>

\section{3-iodo-1-isopropyl-1H-pyrazolo[3,4-d]pyrimidine-4,6-diamine}

A suspension of 4-chloro-3-iodo-1-isopropyl-1H-pyrazolo[3,4- $d$ ]pyrimidin-6-ylamine (1.50 g, 4.44 mmol, 1.00 eq.) in 1,4-dioxane ( $7.95 \mathrm{ml})$ and ammonia $(7.10 \mathrm{ml}, 32.00 \% \mathrm{w} / \mathrm{w}, 13.33 \mathrm{mmol}, 3.00 \mathrm{eq}$. was heated at $100^{\circ} \mathrm{C}$ for $4 \mathrm{~h}$ and allowed to cool to room temperature during the night. The solid formed was collected by filtration and dried to a constant weight to afford the title compoud ( $1.38 \mathrm{~g}$, 97\%) as a white solid: : LCMS ( $t_{\mathrm{R}}=0.70 \mathrm{~min}$., purity= 98\%), ESI+ $\mathrm{m} / \mathrm{z} 319(\mathrm{M}+\mathrm{H})^{+} ;{ }^{1} \mathrm{H}$ NMR $\left(\right.$ DMSO- $\left.d_{6}\right) \delta$ $1.36(\mathrm{~d}, J=6.6 \mathrm{~Hz}, 6 \mathrm{H}), 4.73(\mathrm{~h}, J=6.6 \mathrm{~Hz}, 1 \mathrm{H}), 6.26(\mathrm{br} \mathrm{s}, 2 \mathrm{H}), 7.02(\mathrm{br} \mathrm{s}, 2 \mathrm{H})$.

\section{3-(2-Aminobenzo[d]oxazol-5-yl)-1-isopropyl-1H-pyrazolo[3,4-d]pyrimidine-4,6-diamine (3j)}

In a microwave tube, were added 3-iodo-1-isopropyl-1H-pyrazolo[3,4- $d$ ]pyrimidine-4,6-diamine (700 $\mathrm{mg}, 2.20 \mathrm{mmol}, 1.00$ eq.), 5-(4,4,5,5-tetramethyl-1,3,2-dioxaborolan-2-yl)benzo[d]oxazol-2-amine ( $858 \mathrm{mg}, 3.30 \mathrm{mmol}, 1.50$ eq.) and a $2.0 \mathrm{M}$ aqueous solution of potassium carbonate $(3.30 \mathrm{ml}, 6.60$ mmol, 3.00 eq.) in 1,4-dioxane $(7.35 \mathrm{ml})$ and the reaction mixture was degassed and purged with argon. 1,1'-Bis(diphenylphosphino)ferrocenepalladium(ii) dichloride, dichloromethane (180 mg, 0.22 mmol, 0.10 eq.) was added and the reaction mixture was heated at $100{ }^{\circ} \mathrm{C}$ under microwave irradiation. The reaction mixture was allowed to cool to room temperature, filtered and the filtrated was diluted with EtOAc and water. The organic phase was washed with brine, filtered and dried over $\mathrm{MgSO}_{4}$ and concentrated to dryness. The residue was suspended in DCM and collected by filtration then suspended in not $\mathrm{MeOH}$ in the presence of activated charcoal. The suspension was filtered and a solid crystalised that was collected by filtration, dried to a constant weight to afford the title compound ( $3 \mathbf{j}, 285 \mathrm{mg}, 40 \%)$ as an off-white solid: LCMS ( $t_{\mathrm{R}}=0.66 \mathrm{~min}$., purity= 100\%), ESI+ m/z 325 $(\mathrm{M}+\mathrm{H})^{+} ;{ }^{1} \mathrm{H}$ NMR (DMSO- $\left.d_{6}\right) \delta 1.43(\mathrm{~d}, J=6.7 \mathrm{~Hz}, 6 \mathrm{H}), 4.79-4.85(\mathrm{p}, J=6.7 \mathrm{~Hz}, 1 \mathrm{H}), 6.14(\mathrm{~s}, 2 \mathrm{H}), 7.18-$ $7.21(\mathrm{dd}, J=8.1-1.7 \mathrm{~Hz}, 1 \mathrm{H}), 7.36(\mathrm{~d}, J=1.7 \mathrm{~Hz}, 1 \mathrm{H}), 7.43(\mathrm{~d}, J=8.1 \mathrm{~Hz}, 1 \mathrm{H}), 7.50(\mathrm{~s}, 2 \mathrm{H})$.

HRMS (ESI) calculated for $\mathrm{C}_{15} \mathrm{H}_{16} \mathrm{~N}_{8} \mathrm{O}[\mathrm{M}+\mathrm{H}]^{+} 325.1520$, found 325.1518 . 
diamine (3k)

The title compound $\mathbf{3 k}$ was prepared directly from previously described $\mathbf{3 e}$ :

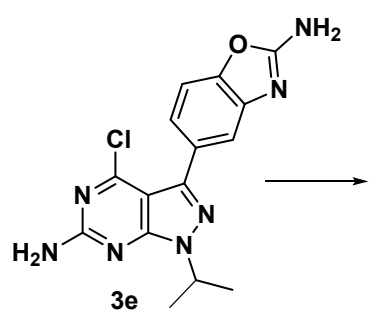<smiles>CC(C)n1nc(-c2ccc3oc(N)nc3c2)c2cnc(N)nc21</smiles>

5-(6-Amino-4-chloro-1-isopropyl-1H-pyrazolo[3,4- $d$ ] pyrimidin-3-yl)benzo[d]oxazol-2-amine $(30 \mathrm{mg}$, $0.09 \mathrm{mmol}, 1.00$ eq.) was dissolved in $\mathrm{MeOH}(0.30 \mathrm{ml})$ and the reaction mixture was degassed then $10 \% \mathrm{Pd}-\mathrm{C}$ ( $18.6 \mathrm{mg}, 0.01 \mathrm{mmol}, 0.10$ eq.) was added. The reaction mixture was degassed and purged with hydrogen and stirred at room temperature for $48 \mathrm{~h}$. The reaction mixture was filtered through a pad of Celite, concentrated to dryness and purified by mass-triggered preparative LCMS (basic conditions) to afford the title compound ( $3 k, 7.9 \mathrm{mg}, 29 \%)$ : LCMS ( $t_{\mathrm{R}}=0.86 \mathrm{~min}$., purity= $\left.100 \%\right)$, ESI+ $\mathrm{m} / \mathrm{z} 310(\mathrm{M}+\mathrm{H})^{+} ;{ }^{1} \mathrm{H}$ NMR (DMSO- $\left.d_{6}\right) \delta 1.41(\mathrm{~d}, J=6.7 \mathrm{~Hz}, 6 \mathrm{H}), 4.77-4.83(\mathrm{hp}, J=6.7 \mathrm{~Hz}, 1 \mathrm{H}), 6.12(\mathrm{~s}$, $2 \mathrm{H}), 7.14-7.19(\mathrm{dd}, J=8.1-1.7 \mathrm{~Hz}, 1 \mathrm{H}), 7.34(\mathrm{~d}, J=1.7 \mathrm{~Hz}, 1 \mathrm{H}), 7.43(\mathrm{~d}, J=8.1 \mathrm{~Hz}, 1 \mathrm{H}), 7.49(\mathrm{~s}, 2 \mathrm{H})$, $8.72(\mathrm{~s}, 1 \mathrm{H})$.

HRMS (ESI) calculated for $\mathrm{C}_{15} \mathrm{H}_{15} \mathrm{~N}_{7} \mathrm{O}[\mathrm{M}+\mathrm{H}]^{+} 310.1411$, found 310.1409 
Preparation of 6-Amino-3-(2-aminobenzo[d]oxazol-5-yl)-1-isopropyl-1,5-dihydro-4H-pyrazolo[3,4d]pyrimidin-4-one (6a)

The title compound $\mathbf{6}$ a was prepared directly from previously described $\mathbf{3 d}$ :<smiles>COc1nc(N)nc2c1c(-c1ccc3oc(N)nc3c1)nn2C(C)C</smiles>

3d<smiles>CC(C)n1nc(-c2ccc3oc(N)nc3c2)c2c(=O)[nH]c(N)nc21</smiles>

compound (6a)<smiles>CC(C)n1nc(-c2ccc3oc(N)nc3c2)c2c(=O)[nH]c(N)nc21</smiles>

6-Amino-3-(2-aminobenzo[d]oxazol-5-yl)-1-isopropyl-1,5-dihydro-4H-pyrazolo[3,4-d]pyrimidin-4one (6a)

5-(6-Amino-1-isopropyl-4-methoxy-1H-pyrazolo[3,4- $d$ ] pyrimidin-3-yl)benzo[d]oxazol-2-amine 3d (67 $\mathrm{mg}, 0.20 \mathrm{mmol}, 1.00$ eq.) was dissolved in $\mathrm{DCM}(0.5 \mathrm{ml})$ and cooled down to $0^{\circ} \mathrm{C}$ for $30 \mathrm{~min}$. A $1.0 \mathrm{M}$ solution of $\mathrm{BBr}_{3}$ in $\mathrm{DCM}(0.33 \mathrm{ml}, 0.33 \mathrm{mmol}, 3.00$ eq.) was added and the reaction mixture was stirred at room temperature overnight under argon. The reaction mixture was quenched with water and extracted into DCM. The organic phases were combined, dried over $\mathrm{MgSO}_{4}$ and concentrated to dryness. The residue was purified by mass-triggered preparative LCMS (acidic conditions) to afford the title compound $\left(6 \mathrm{a}, 3.3 \mathrm{mg}, 5 \%\right.$ ) as an orange solid. LCMS (purity= 97\%), ESI+ m/z $326(\mathrm{M}+\mathrm{H})^{+} ;{ }^{1} \mathrm{H}$ NMR (DMSO-d $\left.d_{6}\right) \delta 1.43(\mathrm{~d}, J=6.6 \mathrm{~Hz}, 6 \mathrm{H}), 4.79(\mathrm{~h}, J=6.7 \mathrm{~Hz}, 1 \mathrm{H}), 6.67(\mathrm{~s}, 2 \mathrm{H}), 7.32(\mathrm{~d}, J=8.5 \mathrm{~Hz}, 1 \mathrm{H})$, $7.38(\mathrm{~s}, 2 \mathrm{H}), 8.00(\mathrm{dd}, J=8.4,1.7 \mathrm{~Hz}, 1 \mathrm{H}), 8.24(\mathrm{~d}, J=1.7 \mathrm{~Hz}, 1 \mathrm{H}), 10.68(\mathrm{~s}, 1 \mathrm{H})$.

HRMS (ESI) calculated for $\mathrm{C}_{15} \mathrm{H}_{15} \mathrm{~N}_{7} \mathrm{O}_{2}[\mathrm{M}+\mathrm{H}]^{+} 326.1360$, found 326.1359 .

\section{Preparation of:}

- 3-(2-Aminobenzo[d]oxazol-5-yl)-1-isopropyl-6-(methylamino)-1,5-dihydro-4Hpyrazolo[3,4-d]pyrimidin-4-one (6b)

- 3-(2-Aminobenzo[d]oxazol-5-yl)-6-(dimethylamino)-1-isopropyl-1,5-dihydro-4Hpyrazolo[3,4-d]pyrimidin-4-one (6c)

The compounds $\mathbf{6 b}$ and $\mathbf{6 c}$ were prepared following the sequence below: 

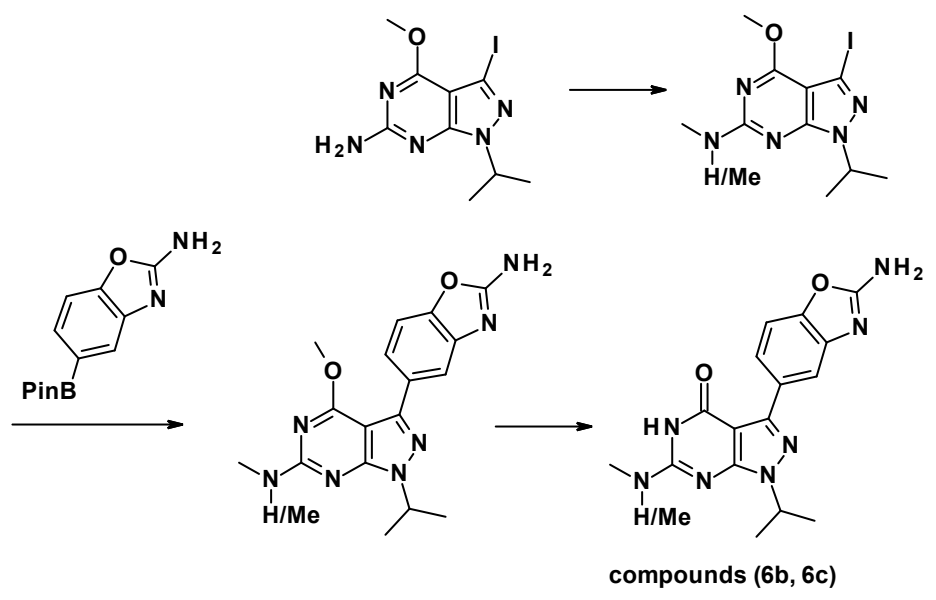

\section{3-iodo-1-isopropyl-4-methoxy- $N$-methyl-1H-pyrazolo[3,4-d]pyrimidin-6-amine}

To a stirred solution of 3-lodo-1-isopropyl-4-methoxy-1H-pyrazolo[3,4-d]pyrimidin-6-amine (100 mg, $0.30 \mathrm{mmol}, 1.00$ eq.) in anhydrous THF $(1.0 \mathrm{ml})$ under argon was added at $0^{\circ} \mathrm{C}$ iodomethane $(20.6 \mu \mathrm{l}$, $0.33 \mathrm{mmol}, 1.10$ eq.). The reaction mixture was stirred at $0^{\circ} \mathrm{C}$ for $5 \mathrm{~min}$ before the addition of sodium hydride (13.21 의, $0.33 \mathrm{mmol}, 1.10$ eq.). Then, the reaction mixture was stirred at room temperature for 6 hours, quenched with a saturated solution of ammonium chloride and extracted into EtOAc. The organic phases were washed with brine, dried over $\mathrm{MgSO}_{4}$ and concentrated to dryness. The residue was purified by flash chromatography (silica gel, heptane:EtOAc 9:1) to afford the title compound (51 mg, 49\%) as an orange solid: LCMS (purity=97\%), ESI+ m/z $348(M+H)^{+} ;{ }^{1} \mathrm{H}$ NMR (DMSO-d $\left.d_{6}\right) \delta 1.39(\mathrm{~d}, J=6.7 \mathrm{~Hz}, 6 \mathrm{H}), 2.82(\mathrm{~d}, J=4.4 \mathrm{~Hz}, 3 \mathrm{H}), 3.96(\mathrm{~s}, 3 \mathrm{H}), 4.82(\mathrm{~s}, 1 \mathrm{H}), 7.32(\mathrm{~s}, 1 \mathrm{H})$

\section{5-(1-isopropyl-4-methoxy-6-(methylamino)-1H-pyrazolo[3,4-d]pyrimidin-3-yl)benzo[d]oxazol-2- amine}

In a microwave tube, 3-iodo-1-isopropyl-4-methoxy- $N$-methyl-1H-pyrazolo[3,4-d]pyrimidin-6-amine ( $50.0 \mathrm{mg}, 0.22 \mathrm{mmol}, 1.00$ eq.) and a $2.0 \mathrm{M}$ aqueous solution of potassium carbonate $(0.22 \mathrm{ml}, 0.43$ mmol, 3.00 eq.) in 1,4-dioxane $(0.8 \mathrm{ml})$ were degassed and purged with argon. 1,1'Bis(diphenylphosphino)ferrocenepalladium(II) dichloride.dichloromethane $(11.8 \mathrm{mg}, 0.01 \mathrm{mmol}, 0.10$ eq.) was added followed by 5-(4,4,5,5-tetramethyl-1,3,2-dioxaborolan-2-yl)benzo[d]oxazol-2-amine (56.2 mg, $0.22 \mathrm{mmol}, 1.50$ eq.) and the reaction mixture was heated at $100{ }^{\circ} \mathrm{C}$ for $30 \mathrm{~min}$. The reaction mixture was cooled to room temperature. Water and EtOAc were added and the organic phase was extracted with EtOAc. The organic phases were washed with brine, dried over $\mathrm{MgSO}_{4}$ and concentrated to dryness to afford the title compound (87 mg, 99\%). 5-(1-isopropyl-4-methoxy-6(methylamino)-1H-pyrazolo[3,4- $d$ ] pyrimidin-3-yl)benzo[d]oxazol-2-amine was directly used in the next step without further purification. ; LCMS (purity= 97\%), ESI+ m/z $354(M+H)^{+}$.

\section{3-(2-Aminobenzo[d]oxazol-5-yl)-1-isopropyl-6-(methylamino)-1,5-dihydro-4H-pyrazolo[3,4-} d]pyrimidin-4-one (6b)

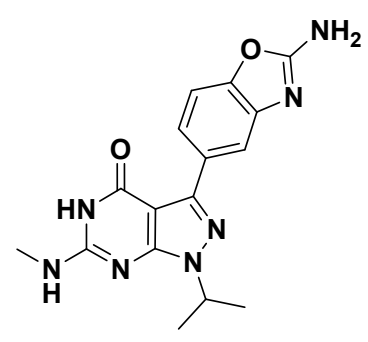

6b 
5-(1-isopropyl-4-methoxy-6-(methylamino)-1H-pyrazolo[3,4- $d$ ] pyrimidin-3-yl)benzo[d]oxazol-2-amine $\left(67 \mathrm{mg}, 0.11 \mathrm{mmol}, 1.00\right.$ eq.) was dissolved in $\mathrm{DCM}(0.4 \mathrm{ml})$ and cooled down to $0^{\circ} \mathrm{C}$ for $30 \mathrm{~min}$. A 1.0 $\mathrm{M}$ solution of $\mathrm{BBr}_{3}$ in $\mathrm{DCM}(0.33 \mathrm{ml}, 0.33 \mathrm{mmol}, 3.00$ eq.) was added and the reaction mixture was stirred at room temperature overnight under argon. The reaction mixture was quenched with water and extracted into DCM. The organic phases were combined, dried over $\mathrm{MgSO}_{4}$ and concentrated to dryness. The residue was purified by mass-triggered preparative LCMS (acidic conditions) to afford the title compound $(2.0 \mathrm{mg}, 5 \%)$ as a white solid. LCMS (purity= 97\%), ESI+ m/z $340(\mathrm{M}+\mathrm{H})^{+} ;{ }^{1} \mathrm{H}$ NMR (DMSO- $\left.d_{6}\right) \delta 1.45(\mathrm{~d}, J=6.7 \mathrm{~Hz}, 6 \mathrm{H}), 2.86(\mathrm{~d}, J=4.7 \mathrm{~Hz}, 3 \mathrm{H}), 4.85(\mathrm{~h}, J=6.7 \mathrm{~Hz}, 1 \mathrm{H}), 6.40(\mathrm{~s}, 1 \mathrm{H}), 7.32$ $(\mathrm{d}, J=8.3 \mathrm{~Hz}, 1 \mathrm{H}), 7.38(\mathrm{~s}, 2 \mathrm{H}), 8.00(\mathrm{dd}, J=8.3,1.7 \mathrm{~Hz}, 1 \mathrm{H}), 8.24(\mathrm{~d}, J=1.7 \mathrm{~Hz}, 1 \mathrm{H}), 10.65(\mathrm{~s}, 1 \mathrm{H})$.

HRMS (ESI) calculated for $\mathrm{C}_{16} \mathrm{H}_{17} \mathrm{~N}_{7} \mathrm{O}_{2}[\mathrm{M}+\mathrm{H}]^{+} 340.1516$, found 340.1515 .

Preparation of 3-(2-Aminobenzo[d]oxazol-5-yl)-6-(dimethylamino)-1-isopropyl-1,5-dihydro-4Hpyrazolo[3,4- $d]$ pyrimidin-4-one (6c)

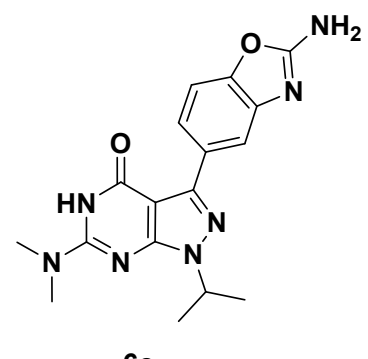

$6 c$

\section{3-iodo-1-isopropyl-4-methoxy-N,N-dimethyl-1H-pyrazolo[3,4-d]pyrimidin-6-amine}

To a stirred solution of 3-lodo-1-isopropyl-4-methoxy-1H-pyrazolo[3,4-d]pyrimidin-6-amine (150 mg, $0.45 \mathrm{mmol}, 1.00$ eq.) in anhydrous THF $(1.1 \mathrm{ml})$ under argon was added at $0^{\circ} \mathrm{C}$ iodomethane $(60 \mu \mathrm{l}$, $0.99 \mathrm{mmol}, 2.20$ eq.). The reaction mixture was stirred at $0^{\circ} \mathrm{C}$ for $5 \mathrm{~min}$ before the addition of sodium hydride (39.6 $\mathrm{mg}, 0.99 \mathrm{mmol}, 2.20$ eq.). Then, the reaction mixture was stirred at room temperature for 6 hours, quenched with a saturated solution of ammonium chloride and extracted into EtOAc. The organic phases were washed with brine, dried over $\mathrm{MgSO}_{4}$ and concentrated to dryness. The residue was purified by flash chromatography (silica gel, heptane:EtOAc 9:1) to afford the title compound (154 mg, 95\%) as an orange solid: LCMS (purity=97\%), ESI+ m/z $362(\mathrm{M}+\mathrm{H})^{+} ;{ }^{1} \mathrm{H}$ NMR $\left(\right.$ DMSO- $\left._{6}\right) \delta 1.40(\mathrm{~d}, J=6.7 \mathrm{~Hz}, 6 \mathrm{H}), 3.17(\mathrm{~s}, 6 \mathrm{H}), 4.01(\mathrm{~s}, 3 \mathrm{H}), 4.84(\mathrm{p}, J=6.6 \mathrm{~Hz}, 1 \mathrm{H})$.

\section{3-(2-Aminobenzo[d]oxazol-5-yl)-6-(dimethylamino)-1-isopropyl-1,5-dihydro-4H-pyrazolo[3,4- d]pyrimidin-4-one $(6 c)$}

In a microwave tube, 3-iodo-1-isopropyl-4-methoxy- $\mathrm{N}, \mathrm{N}$-dimethyl-1H-pyrazolo[3,4- $d$ ] pyrimidin-6amine ( $165.0 \mathrm{mg}, 0.46 \mathrm{mmol}, 1.00 \mathrm{eq}$.) and a $2.0 \mathrm{M}$ aqueous solution of potassium carbonate $(685 \mu \mathrm{l}$, $1.37 \mathrm{mmol}, 3.00$ eq.) in 1,4-dioxane $(2.5 \mathrm{ml})$ were degassed and purged with argon. 1,1'Bis(diphenylphosphino)ferrocenepalladium(II) dichloride.dichloromethane $(37.3 \mathrm{mg}, 0.05 \mathrm{mmol}, 0.10$ eq.) was added followed by 5-(4,4,5,5-tetramethyl-1,3,2-dioxaborolan-2-yl)benzo[d]oxazol-2-amine (178 mg, $0.69 \mathrm{mmol}, 1.50$ eq.) and the reaction mixture was heated at $100{ }^{\circ} \mathrm{C}$ for $30 \mathrm{~min}$. The reaction mixture was cooled to room temperature. Water and EtOAc were added and the organic phase was extracted with EtOAc. The organic phases were washed with brine, dried over $\mathrm{MgSO}_{4}$ and concentrated to dryness to afford the title compound (167mg, 99\%). 5-(6-(dimethylamino)-1isopropyl-4-methoxy-1H-pyrazolo[3,4- $d$ ] pyrimidin-3-yl)benzo[d]oxazol-2-amine was directly used in the next step without further purification; LCMS (purity=97\%), ESI+ m/z $368(M+H)^{+}$. 
To 5-(6-(dimethylamino)-1-isopropyl-4-methoxy-1H-pyrazolo[3,4-d]pyrimidin-3-yl)benzo[d]oxazol-2amine ( $95.0 \mathrm{mg}, 0.26 \mathrm{mmol}, 1.00$ eq.) was added a $4 \mathrm{M}$ solution of hydrogen chloride in dioxane (0.65 $\mathrm{ml}, 2.59 \mathrm{mmol}, 10.0$ eq.). The mixture was stirred for 2 hours at room temperature and cooled down to $0^{\circ} \mathrm{C}$ to be quenched with a saturated solution of $\mathrm{NaHCO}_{3}$ and extracted into AcOEt. The organic phases were combined, dried over $\mathrm{MgSO}_{4}$ and concentrated to dryness. The residue was precipitated in DMF, filtrated and washed with water to obtain the title compound $(\mathbf{6 d}, 16.8 \mathrm{mg}, 18 \%)$ as a white solid. LCMS (purity= 97\%), ESI+ m/z $354(\mathrm{M}+\mathrm{H})^{+} ;{ }^{1} \mathrm{H}$ NMR (DMSO- $\left.d_{6}\right) \delta 1.45(\mathrm{~d}, J=6.7 \mathrm{~Hz}, 6 \mathrm{H}), 3.11(\mathrm{~s}$, $6 \mathrm{H}), 4.84(\mathrm{~h}, J=6.7 \mathrm{~Hz}, 1 \mathrm{H}), 7.34(\mathrm{~d}, J=8.3 \mathrm{~Hz}, 1 \mathrm{H}), 7.38(\mathrm{~s}, 2 \mathrm{H}), 7.99(\mathrm{dd}, J=8.4,1.7 \mathrm{~Hz}, 1 \mathrm{H}), 8.25(\mathrm{~d}$, $J=1.7 \mathrm{~Hz}, 1 \mathrm{H}), 10.60(\mathrm{~s}, 1 \mathrm{H})$.

HRMS (ESI) calculated for $\mathrm{C}_{17} \mathrm{H}_{19} \mathrm{~N}_{7} \mathrm{O}_{2}[\mathrm{M}+\mathrm{H}]^{+} 354.1673$, found 354.1670 .

\section{Preparation of 3-(2-Aminobenzo[d]oxazol-5-yl)-1-isopropyl-6-methyl-1,5-dihydro-4H-pyrazolo[3,4- d]pyrimidin-4-one (6d)}

Compound $\mathbf{6 d}$ was prepared following the sequence below:

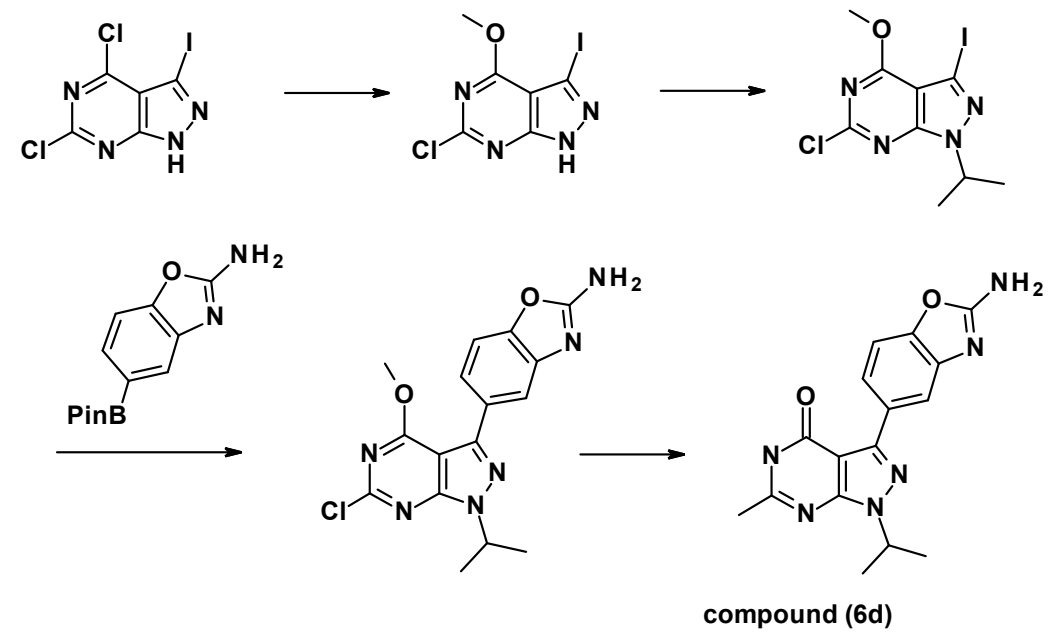

\section{5-(6-chloro-1-isopropyl-4-methoxy-1H-pyrazolo[3,4-d]pyrimidin-3-yl)benzo[d]oxazol-2-amine}

To a stirred solution of 4,6-dichloro-3-iodo- $1 \mathrm{H}$-pyrazolo[3,4- $d$ ] pyrimidine $(400.0 \mathrm{mg}, 1.27 \mathrm{mmol}, 1.00$ eq.) in $\mathrm{MeOH}(2.4 \mathrm{ml})$ was added $30 \%$ solution of sodium methoxide in $\mathrm{MeOH}(0.25 \mathrm{ml}, 1.33 \mathrm{mmol}$, 1.05 eq.). The reaction mixture was stirred at room temperature overnight, quenched with a saturated solution of ammonium chloride and extracted into EtOAc. The organic phases were washed with brine, dried over $\mathrm{MgSO}_{4}$ and concentrated to dryness to afford the title compound (385 $\mathrm{mg}, 97 \%$ ) as a white solid: LCMS (purity= 99\%), ESI+ m/z $311(\mathrm{M}+\mathrm{H})^{+}$. 6-Chloro-3-iodo-4-methoxy-1Hpyrazolo[3,4- $d$ ] pyrimidine was engaged in the next step without further purification.

2-lodopropane (106.3 ml, $1.06 \mathrm{mmol}, 1.10$ eq.) was added to a stirred solution of 6-Chloro-3-iodo-4methoxy-1H-pyrazolo[3,4- $d$ ]pyrimidine $(7.92 \mathrm{~g}, 37.0 \mathrm{mmol}, 1.00 \mathrm{eq}$.) and cesium carbonate (346.0 $\mathrm{mg}, 1.06 \mathrm{mmol}, 1.10$ eq.) in DMF ( $3 \mathrm{ml}$ ). The reaction mixture was stirred at room temperature for 2 hours, filtered and the filtrate was purified by flash chromatography over silica gel. The fractions were evaporated and the residue crystallised from heptane/EtOAc. The solid was collected by filtration and dried to a constant weight to afford the title compound (170 mg, 49\%) as a beige solid: 
LCMS (purity= 99\%), ESI+ m/z $353(\mathrm{M}+\mathrm{H})^{+} .6$-Chloro-3-iodo-1-isopropyl-4-methoxy-1H-pyrazolo[3,4d]pyrimidin was engaged in the next step without further purification.

In a microwave tube, 6-Chloro-3-iodo-1-isopropyl-4-methoxy-1H-pyrazolo[3,4- $d$ ]pyrimidine (170.0 $\mathrm{mg}, 0.48 \mathrm{mmol}, 1.00$ eq.) and a $2.0 \mathrm{M}$ aqueous solution of potassium carbonate $(724 \mu \mathrm{l}, 1.45 \mathrm{mmol}$, 3.00 eq.) in 1,4-dioxane $(1.7 \mathrm{ml})$ were degassed and purged with argon. 1,1'Bis(diphenylphosphino)ferrocenepalladium(II) dichloride.dichloromethane $(39.4 \mathrm{mg}, 0.05 \mathrm{mmol}, 0.10$ eq.) was added followed by 5-(4,4,5,5-tetramethyl-1,3,2-dioxaborolan-2-yl)benzo[d]oxazol-2-amine (188 mg, $0.72 \mathrm{mmol}, 1.50$ eq.) and the reaction mixture was heated at $100{ }^{\circ} \mathrm{C}$ for $30 \mathrm{~min}$. The reaction mixture was cooled to room temperature. Water and EtOAc were added and the organic phase was extracted with EtOAc. The organic phases were washed with brine, dried over $\mathrm{MgSO}_{4}$ and concentrated to dryness. The residue was purified by mass-triggered preparative LCMS (acidic conditions) to afford the title compound $(29.0 \mathrm{mg}, 16 \%)$ as a white solid.; LCMS (purity= 97\%), ESI+ $\mathrm{m} / \mathrm{z} 359(\mathrm{M}+\mathrm{H})^{+} .{ }^{1} \mathrm{H}$ NMR (DMSO- $\left.d_{6}\right) \delta 1.53(\mathrm{~d}, J=6.6 \mathrm{~Hz}, 6 \mathrm{H}), 4.12(\mathrm{~s}, 3 \mathrm{H}), 5.03-5.12(\mathrm{~m}, 1 \mathrm{H}), 7.44$ $(\mathrm{d}, J=8.3 \mathrm{~Hz}, 1 \mathrm{H}), 7.50(\mathrm{~s}, 2 \mathrm{H}), 7.61(\mathrm{dd}, J=8.3,1.8 \mathrm{~Hz}, 1 \mathrm{H}), 7.77(\mathrm{~d}, J=1.7 \mathrm{~Hz}, 1 \mathrm{H})$.

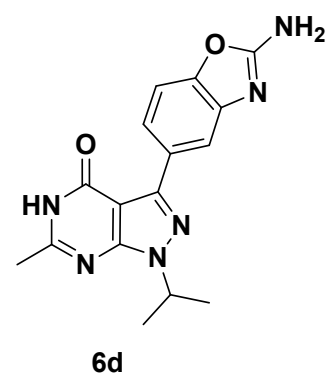

3-(2-Aminobenzo[d]oxazol-5-yl)-1-isopropyl-6-methyl-1,5-dihydro-4H-pyrazolo[3,4-d]pyrimidin-4one $(6 d)$

5-(6-chloro-1-isopropyl-4-methoxy-1H-pyrazolo[3,4-d]pyrimidin-3-yl)benzo[d]oxazol-2-amine $(29.0 \mathrm{mg}, \quad 0.08 \mathrm{mmol}, 1.00 \mathrm{eq}$.) was dissolved in THF $(150 \mu \mathrm{l})$ and bis(tri-tbutylphosphine)palladium(0) $\left(8.3 \mathrm{mg}, 0.02 \mathrm{mmol}, 0.20\right.$ eq.) was added at $0{ }^{\circ} \mathrm{C}$. The reaction mixture was degassed and purged with argon and $1 \mathrm{M}$ solution of dimethylzinc in heptane $(245 \mu \mathrm{l}, 0.24 \mathrm{mmol}$, 3.00 eq.) was added keeping the temperature at $0{ }^{\circ} \mathrm{C}$. The reaction mixture was stirred at room temperature overnight, quenched with a saturated aqueous solution of ammonium chloride and extracted with EtOAc. The organic phase was washed with brine, dried over $\mathrm{MgSO}_{4}$ and concentrated to dryness. A 4M solution of hydrogen chloride in dioxane $(0.20 \mathrm{ml}, 0.81 \mathrm{mmol}, 10.0$ eq.) was added to the residue and the mixture stirred for 5 hours at room temperature. The crude mixture is diluted with DMF and purified by mass-triggered preparative HPLC (acidic method) to afford the title compound $(3.0 \mathrm{mg}, 11 \%)$ as a white solid: LCMS (purity=97\%), ESI+ m/z $339(\mathrm{M}+\mathrm{H})^{+} ;{ }^{1} \mathrm{H}$ NMR $(400$ $\left.\mathrm{MHz}, \mathrm{DMSO}-d_{6}\right) \delta 1.47(\mathrm{~d}, J=6.6 \mathrm{~Hz}, 6 \mathrm{H}), 2.38(\mathrm{~s}, 3 \mathrm{H}), 5.00(\mathrm{p}, J=6.6 \mathrm{~Hz}, 1 \mathrm{H}), 7.36(\mathrm{~d}, J=8.4 \mathrm{~Hz}, 1 \mathrm{H})$, $7.42(\mathrm{~s}, 2 \mathrm{H}), 8.03(\mathrm{dd}, J=8.3,1.7 \mathrm{~Hz}, 1 \mathrm{H}), 8.26(\mathrm{~d}, J=1.7 \mathrm{~Hz}, 1 \mathrm{H}), 12.07(\mathrm{~s}, 1 \mathrm{H})$.

HRMS (ESI) calculated for $\mathrm{C}_{16} \mathrm{H}_{16} \mathrm{~N}_{6} \mathrm{O}_{2}[\mathrm{M}+\mathrm{H}]^{+} 325.1408$, found 325.1404 .

\section{Preparation of 3-(2-aminobenzo[d]oxazol-5-yl)-1-isopropyl-1,5-dihydro-4H-pyrazolo[3,4- d]pyrimidin-4-one (6e)}

The compounds $6 \mathrm{e}$ was prepared following the sequence below: 

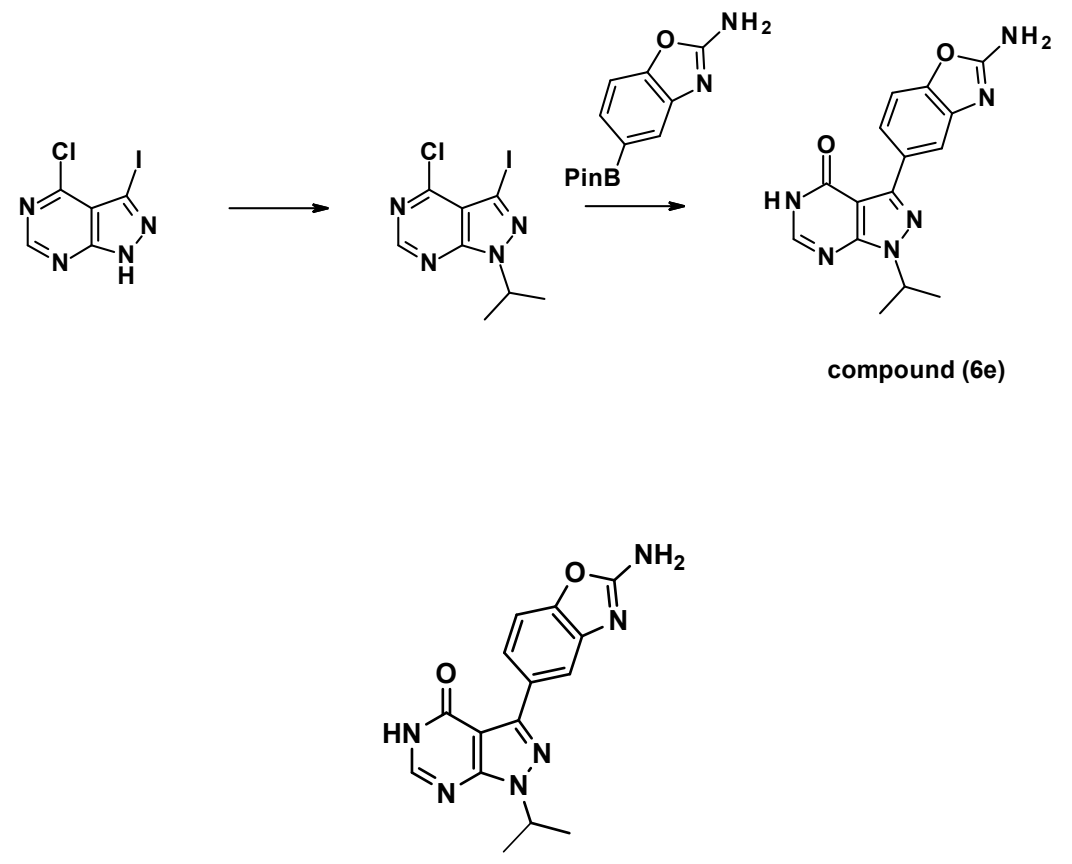

$6 e$

\section{3-(2-aminobenzo[d]oxazol-5-yl)-1-isopropyl-1,5-dihydro-4H-pyrazolo[3,4-d]pyrimidin-4-one (6e)}

2-lodopropane (690 ml, $6.93 \mathrm{mmol}, 1.05$ eq.) was added to a stirred solution of commercially available 6-Chloro-3-iodo- $1 \mathrm{H}$-pyrazolo[3,4-d]pyrimidine $(1.85 \mathrm{~g}, 6.60 \mathrm{mmol}, 1.00 \mathrm{eq}$.) and cesium carbonate $(4.30 \mathrm{~g}, 13.19 \mathrm{mmol}, 2.0$ eq. $)$ in DMF $(35 \mathrm{ml})$. The reaction mixture was stirred at room temperature for 2 hours, filtered and the filtrate was purified by flash chromatography over silica gel. The fractions were evaporated and the residue crystallised from heptane / EtOAc. The solid was collected by filtration and dried to a constant weight to afford the title compound $(1.80 \mathrm{~g}, 82 \%)$ as a beige solid: LCMS (purity= 95\%), ESI+ m/z $323(\mathrm{M}+\mathrm{H})^{+} ;{ }^{1} \mathrm{H}$ NMR (DMSO- $\left.d_{6}\right) \delta 1.51(\mathrm{~d}, J=6.6 \mathrm{~Hz}, 6 \mathrm{H}$ ), $5.04(\mathrm{p}, J=6.7 \mathrm{~Hz}, 1 \mathrm{H}), 9.43(\mathrm{~s}, 1 \mathrm{H})$. 6-Chloro-3-iodo-1-isopropyl-4-methoxy-1H-pyrazolo[3,4d]pyrimidin was engaged in the next step without further purification.

In a microwave tube, 4-chloro-3-iodo-1-isopropyl-1H-pyrazolo[3,4-d]pyrimidine $(92.0 \mathrm{mg}, 0.29 \mathrm{mmol}$, 1.00 eq.) and a $2.0 \mathrm{M}$ aqueous solution of potassium carbonate $(430 \mu \mathrm{l}, 0.86 \mathrm{mmol}, 3.00$ eq.) in $1,4-$ dioxane $(1.4 \mathrm{ml})$ were degassed and purged with argon. 1,1'Bis(diphenylphosphino)ferrocenepalladium(II) dichloride.dichloromethane $(23.29 \mathrm{mg}, 0.03 \mathrm{mmol}$, 0.10 eq.) was added followed by 5-(4,4,5,5-tetramethyl-1,3,2-dioxaborolan-2-yl)benzo[d]oxazol-2amine $\left(111.3 \mathrm{mg}, 0.43 \mathrm{mmol}, 1.50\right.$ eq.) and the reaction mixture was heated at $100{ }^{\circ} \mathrm{C}$ for 4 hours to obtain complete hydrolysis of the chloride. The reaction mixture was cooled to room temperature. Water and EtOAc were added and the organic phase was extracted with EtOAc. The organic phases were washed with brine, dried over $\mathrm{MgSO}_{4}$ and concentrated to dryness. The residue was purified by mass-triggered preparative LCMS (acidic conditions) to afford the title compound (6e, $10.0 \mathrm{mg}, 11 \%$ ) as a white solid.; LCMS (purity=97\%), ESI+ $\mathrm{m} / \mathrm{z} 311(\mathrm{M}+\mathrm{H})^{+} .{ }^{1} \mathrm{H}$ NMR (DMSO- $\left.d_{6}\right) \delta 1.51(\mathrm{~d}, J=6.6 \mathrm{~Hz}$, $6 \mathrm{H}), 5.04(\mathrm{p}, J=6.7 \mathrm{~Hz}, 1 \mathrm{H}), 7.38(\mathrm{~d}, J=8.3 \mathrm{~Hz}, 1 \mathrm{H}), 7.44(\mathrm{~s}, 2 \mathrm{H}), 8.02(\mathrm{dd}, J=8.4,1.8 \mathrm{~Hz}, 1 \mathrm{H}), 8.08(\mathrm{~s}$, $1 \mathrm{H}), 8.25(\mathrm{~d}, J=1.7 \mathrm{~Hz}, 1 \mathrm{H}), 12.20(\mathrm{~s}, 1 \mathrm{H})$.

HRMS (ESI) calculated for $\mathrm{C}_{15} \mathrm{H}_{14} \mathrm{~N}_{6} \mathrm{O}_{2}[\mathrm{M}+\mathrm{H}]^{+} 311.1251$, found 311.1250 .

\footnotetext{
${ }^{1}$ Valko, K.; Bevan, C.; Reynolds, D. Chromatographic hydrophobicity index by fast-gradient RP-HPLC: A high-throughput alternative to
} logP/logD. Anal. Chem. 1997, 69, 2022-2029. 
${ }^{2}$ Young, R. J.; Green, D. V. S.; Luscombe, C. N.; Hill, A. P. Getting physical in drug discovery II: the impact of chromatographic hydrophobicity measurements and aromaticity. Drug Disc. Today 2011, 16(17/18), 822-830 